\title{
Phase Behavior in NaSiCON Electrolytes and Electrodes
}

\author{
Zeyu Deng, ${ }^{\dagger}$ Gopalakrishnan Sai Gautam, ${ }^{\ddagger}$ Sanjeev Krishna Kolli, ${ }^{\top}$ Jean-Noël \\ Chotard, ${ }^{\S}, \|$ Anthony K. Cheetham, ${ }^{\dagger, \Phi}$ Christian Masquelier, ${ }^{\S}, \|$ and Pieremanuele \\ Canepa*, ${ }^{*}$ \\ $\dagger$ Department of Materials Science and Engineering, National University of Singapore, 9 \\ Engineering Drive 1, Singapore \\ $\ddagger$ Department of Mechanical and Aerospace Engineering, Princeton University, Princeton, \\ New Jersey 08544, United States \\ ฯ Materials Department and Materials Research Laboratory, University of California, Santa \\ Barbara, California 93106, United States \\ §Laboratoire de Réactivité et Chimie des Solides, UMR CNRS \#7314, Université de \\ Picardie Jules Verne, 80039 Amiens Cedex, France \\ ||RS2E, Réseau Français sur le Stockage Electrochimique de l'Energie, FR CNRS \#3459, \\ F-80039 Amiens Cedex 1, France \\ E-mail: pcanepa@nus.edu.sg
}

\section{Abstract}

The replacement of the presently used liquid electrolytes by a non-flammable solid electrolyte is an important avenue to create safer batteries. The Natrium Superionic CONductor (NaSiCON) $\mathrm{Na}_{1+\mathrm{x}} \mathrm{Zr}_{2} \mathrm{Si}_{\mathrm{x}} \mathrm{P}_{3-\mathrm{x}} \mathrm{O}_{12}(0 \leq x \leq$ 3 ) that displays high bulk ionic conductivity and good stability towards other NaSiCONbased electrodes is a good solid electrolyte in NaSiCON-based batteries. Despite the sizeable share of research on $\mathrm{Na}_{1+\mathrm{x}} \mathrm{Zr}_{2} \mathrm{Si}_{\mathrm{x}} \mathrm{P}_{3-\mathrm{x}} \mathrm{O}_{12}$, the structural and thermodynamic properties of $\mathrm{NaSiCON}$ require better understanding for more efficient synthesis and optimization as a solid electrolyte, which often follows chemical intuition. Here, we analyze the thermodynamic properties of the NaSiCON electrolyte by constructing the $\mathrm{Na}_{1+\mathrm{x}} \mathrm{Zr}_{2} \mathrm{Si}_{\mathrm{x}} \mathrm{P}_{3-\mathrm{x}} \mathrm{O}_{12}$ phase diagram, based on density functional theory calculations, a cluster expansion framework, and Monte Carlo simulations. Specifically, we build the phase diagram as a function of temperature and composition $(0 \leq$ $x \leq 3)$ for the high-temperature rhombohedral structure, which has been also observed in several positive electrode materials, such as $\mathrm{Na}_{3} \mathrm{Ti}_{2}\left(\mathrm{PO}_{4}\right)_{3}, \mathrm{Na}_{3} \mathrm{~V}_{2}\left(\mathrm{PO}_{4}\right)_{3}, \mathrm{Na}_{3} \mathrm{Cr}_{2}\left(\mathrm{PO}_{4}\right)_{3}$, and $\mathrm{Na}_{3} \mathrm{Fe}_{2}\left(\mathrm{PO}_{4}\right)_{3}$. Through the phase diagram, we identify the concentration domains providing the highest $\mathrm{Na}^{+}$-ion conductivity and previously unreported phase-separation behavior across three different single-phase regions. Further, we note the similarities in the phase behavior between $\mathrm{Na}_{1+\mathrm{x}} \mathrm{Zr}_{2} \mathrm{Si}_{\mathrm{x}} \mathrm{P}_{3-\mathrm{x}} \mathrm{O}_{12}$ and other NaSiCON-based mono-transition metal electrodes and discuss the potential competition between thermodynamics and kinetics in experimentally observed phase separation. Our work is an important addition in understanding the thermodynamics of NaSiCON-based materials and in the development of inexpensive Na-ion batteries. From our results we propose that the addition of $\mathrm{SiO}_{4}^{4-}$ moieties to single-transition metal NaSiCON-phosphatebased electrodes will slow significantly the kinetics toward phase separation. 


\section{Introduction}

The development of green energy technologies, such as photovoltaics, wind turbines and rechargeable batteries, is essential in meeting the sustainable needs of a society to limit its fossil fuel usage. Lithium (Li)-ion batteries power the world's mobile devices, and they are increasingly seen in vehicular transportation. When life-cycle analysis is examined in the design of batteries, however, sodium (Na) appears attractive since it can be "harvested" directly from seawater, making $\mathrm{Na} \sim 50$ times lower in cost than $\mathrm{Li}^{1-3} \mathrm{Na}$-ion batteries also use inexpensive, stainless-steel current collectors. $^{2}$ However, commercial Li-ion batteries and the state-of-the-art Na-ion batteries employ highly flammable organic liquid electrolytes, ${ }^{4,5}$ which pose a tangible safety concern in their widespread deployment.

A pathway to create a battery with a high energy density as well as safety is to replace the liquid with a non-flammable solid electrolyte, ${ }^{6}$ leading to all-solid-state batteries, which are the object of a sizeable amount of current research. ${ }^{7-24}$ Today, the superionic conductivity of $\mathrm{Li}^{+}$and $\mathrm{Na}^{+}$-ions in solid electrolytes can achieve record-values $>10 \mathrm{mS} \cdot \mathrm{cm}^{-1}$ at room temperature, ${ }^{25-27,27}$ rivalling those of commercial liquid electrolytes (e.g., $1 \mathrm{M} \mathrm{LiPF}_{6}$ in dimethyl/ethylene carbonates $\left.\sim 10^{-2} \mathrm{~S} \cdot \mathrm{cm}^{-1}\right){ }^{28}$ More than 40 years ago, Hong and Goodenough studied the "Natrium Superionic CONductor" (NaSiCON), $\mathrm{Na}_{1+\mathrm{x}} \mathrm{Zr}_{2} \mathrm{Si}_{\mathrm{x}} \mathrm{P}_{3-\mathrm{x}} \mathrm{O}_{12}(0 \leq x \leq 3),{ }^{29,30}$ which can achieve exceptional bulk ionic $\mathrm{Na}^{+}$-conductivity $\left(\sim 15 \mathrm{mS} \cdot \mathrm{cm}^{-1}\right.$ at $\left.298 \mathrm{~K}\right)$ for $\mathrm{x} \sim 2.0-2.4 .^{31}$ The NaSiCON structure provides a versatile framework, incorporating both cationic $\left(\mathrm{Na}^{+}\right.$and $\mathrm{Zr}^{4+}$ ) and anionic $\left(\mathrm{SiO}_{4}^{4-}\right.$ and $\mathrm{PO}_{4}^{3-}$ ) moieties, ${ }^{32,33}$ which enable the number of $\mathrm{Na}^{+}$-ions to vary between 1 and 4 per formula unit with corresponding changes in the $\mathrm{P}: \mathrm{Si}$ ratio and $\mathrm{Na}^{+}$-ion conductivity.

Figure 1 depicts the structure of the hightemperature $(>450 \mathrm{~K})$ rhombohedral (space group: $R \overline{3} c$ ) phase of $\mathrm{Na}_{1+\mathrm{x}} \mathrm{Zr}_{2} \mathrm{Si}_{\mathrm{x}} \mathrm{P}_{3-\mathrm{x}} \mathrm{O}_{12},{ }^{29,30,32,33}$ where the 3 blue $\mathrm{XO}_{4}(\mathrm{X}=\mathrm{P}$ or $\mathrm{Si})$ tetrahedra share corners with two grey $\mathrm{ZrO}_{6}$ oc- tahedra forming the so-called "lantern units" (panels $\mathbf{a}$ and $\mathbf{b}$ ). There are two distinct, partially occupied (disordered) sodium sites, $\mathrm{Na}(1)$ and $\mathrm{Na}(2)$ (panel b). The super-ionic behavior in $\mathrm{Na}_{1+\mathrm{x}} \mathrm{Zr}_{2} \mathrm{Si}_{\mathrm{x}} \mathrm{P}_{3-\mathrm{x}} \mathrm{O}_{12}$ is driven by a Na-vacancy migration mechanism that relates directly to the occupational disorder of $\mathrm{Na}(1)$ and $\mathrm{Na}(2) .{ }^{29,34-36}$ The $\mathrm{Na}(1)$ site is typically larger than $\mathrm{Na}(2)$ and is coordinated by oxygens atoms from $\mathrm{ZrO}_{6}$ units in an antiprismatic arrangement (Figure $1 \mathbf{b}$ and 1c), while $\mathrm{Na}(2)$ resides in an irregular polyhedral, coordinated to seven neighboring oxygen atoms from the $\mathrm{ZrO}_{6}$ and $\mathrm{XO}_{4}$ units. The existence of a third $\mathrm{Na}$ site between $\mathrm{Na}(1)$ and $\mathrm{Na}(2)$ has been reported, ${ }^{33,37}$ and attributed to a metastable state in the $\mathrm{Na}^{+}$migration. At lower temperatures $(<450 \mathrm{~K})$ and for $1.8 \leq x \leq 2.2$ for $x$ in $\mathrm{Na}_{1+\mathrm{x}} \mathrm{Zr}_{2} \mathrm{Si}_{\mathrm{x}} \mathrm{P}_{3-\mathrm{x}} \mathrm{O}_{12}$, the NaSiCON undergoes a monoclinic distortion (space group: $C 2 / c$ ) that is often associated with $\mathrm{Na}^{+}$ordering into distinct $\mathrm{Na}$ sites and lower Na-conductivities. ${ }^{29}$ Here, we will use the nomenclature rhombohedral- and monoclinic-NaSiCON to distinguish the two $\mathrm{Na}_{1+\mathrm{x}} \mathrm{Zr}_{2} \mathrm{Si}_{\mathrm{x}} \mathrm{P}_{3-\mathrm{x}} \mathrm{O}_{12}$ phases.

There exists an extensive body of prior literature on optimizing the Na-ion conductivity within the NaSiCON electrolyte, ${ }^{30,31,33,34,36-40}$ especially at $x \sim 2$ in $\mathrm{Na}_{1+\mathrm{x}} \mathrm{Zr}_{2} \mathrm{Si}_{\mathrm{x}} \mathrm{P}_{3-\mathrm{x}} \mathrm{O}_{12}$. Aliovalent doping has been used to increase the $\mathrm{Na}$-ion conductivity by varying the $\mathrm{Na}$ content and disorder in NaSiCON. ${ }^{34,38-40}$ For example, Miyajima et al. ${ }^{41}$ studied the partial substitution of $\mathrm{Zr}^{4+}$ by $3+$ cations, such as $\mathrm{In}^{3+}$, $\mathrm{Yb}^{3+}, \mathrm{Er}^{3+}, \mathrm{Y}^{3+}, \mathrm{Dy}^{3+}, \mathrm{Tb}^{3+}$, and $\mathrm{Gd}^{3+}$ in $\mathrm{Na}_{1+\mathrm{x}} \mathrm{Zr}_{2} \mathrm{Si}_{\mathrm{x}} \mathrm{P}_{3-\mathrm{x}} \mathrm{O}_{12}$ leading to an increase of the $\mathrm{Na}$ content. While $\mathrm{Sc}^{3+}$ has also been used as a common aliovalent dopant on $\mathrm{Zr}^{4+}, 39-41$ high $\mathrm{Na}^{+}$conductivities $\left(\sim 3.7 \mathrm{mS} \cdot \mathrm{cm}^{-1}\right)$ have been achieved by doping with trivalent $\mathrm{Al}^{3+}$, $\mathrm{Fe}^{3+}$, and $\mathrm{Y}^{3+}$, and divalent $\mathrm{Co}^{2+}, \mathrm{Ni}^{2+}$, and $\mathrm{Zn}^{2+}$ species. ${ }^{38}$ The complete substitution of $\mathrm{Zr}^{4+}$ in $\mathrm{NaSiCON}$ by redox-active transition metals, ${ }^{36,38-40}$ e.g., Ti, V, Cr, and $\mathrm{Fe}$, in NaSiCON transforms the solid electrolyte into an electrode. Notably, NaSiCONderived electrodes (e.g., $\quad \mathrm{Na}_{3} \mathrm{Ti}_{2}\left(\mathrm{PO}_{4}\right)_{3}$, $\mathrm{Na}_{3} \mathrm{~V}_{2}\left(\mathrm{PO}_{4}\right)_{3}$ and $\left.\mathrm{Na}_{3} \mathrm{Cr}_{2}\left(\mathrm{PO}_{4}\right)_{3}\right)$ often show 


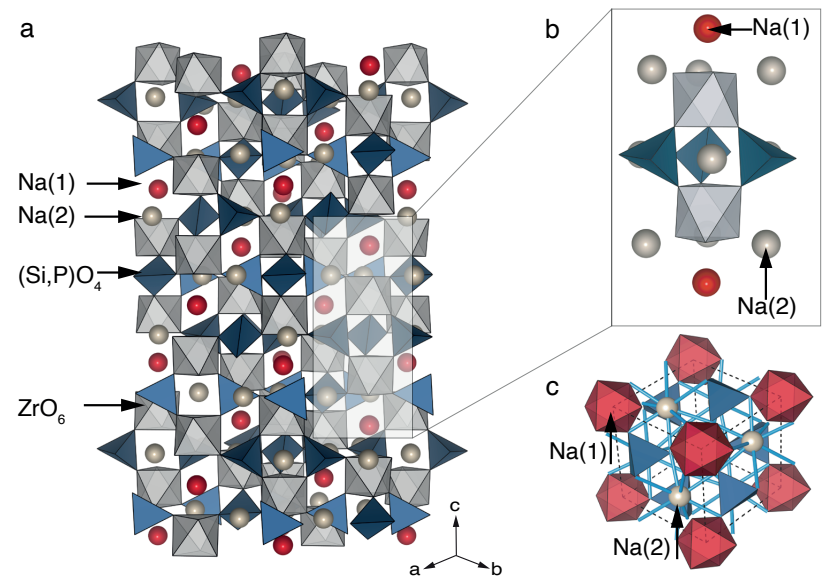

Figure 1: Representation of the rhombohedral $\mathrm{Na}_{1+\mathrm{x}} \mathrm{Zr}_{2} \mathrm{Si}_{\mathrm{x}} \mathrm{P}_{3-\mathrm{x}} \mathrm{O}_{12}$ structure. $\mathrm{Na}(1)$ is represented by red anti-prisms or red spheres, $\mathrm{Na}(2)$ by silver spheres, $(\mathrm{Si} / \mathrm{P}) \mathrm{O}_{4}$ by blue tetrahedra and $\mathrm{ZrO}_{6}$ by grey octahedra. Panel a shows the lantern arrangement, whereby $\mathrm{Na}(1)$ positions are stacked between two $\mathrm{ZrO}_{6}$ octahedra along the [001] direction. Panel $b$ depicts a zoomed view (of panel a) of the $\mathrm{Na}(1)$ and $\mathrm{Na}(2)$ arrangement within the rhombohedral cell. Panel c shows a view down the $c$-axis.

phase-separation behavior upon Na intercalation/extraction. ${ }^{34,42,43,43-47}$

The phase behavior - phase separation or the existence of solid solutions- has not been fully elucidated in $\mathrm{Na}_{1+\mathrm{x}} \mathrm{Zr}_{2} \mathrm{Si}_{\mathrm{x}} \mathrm{P}_{3-\mathrm{x}} \mathrm{O}_{12}$. Specifically, the experimentally observed disorder and fractional occupancies of the $\mathrm{Na} /$ Vacancy (Va) and $\mathrm{Si} / \mathrm{P}$ sites in the rhombohedral-NaSiCON structure $^{29,30,33}$ hinder characterization attempts in assigning specific phases (or ordered $\mathrm{Na}$ configurations) at different temperatures and $\mathrm{Na}$ compositions. In this investigation, we therefore analyze the phase behavior of the NaSiCON electrolyte by constructing the $\mathrm{Na}_{1+\mathrm{x}} \mathrm{Zr}_{2} \mathrm{Si}_{\mathrm{x}} \mathrm{P}_{3-\mathrm{x}} \mathrm{O}_{12}$ phase diagram as a function of composition $(0 \leq x \leq 3)$ and temperature. We focus on the high-temperature rhombohedral-NaSiCON $\quad \mathrm{Na}_{1+\mathrm{x}} \mathrm{Zr}_{2} \mathrm{Si}_{\mathrm{x}} \mathrm{P}_{3-\mathrm{x}} \mathrm{O}_{12}$ structure, which exhibits high Na-conductivity and is adopted by several Na-based positive electrodes (e.g., $\mathrm{Na}_{3} \mathrm{Ti}_{2}\left(\mathrm{PO}_{4}\right)_{3}, \mathrm{Na}_{3} \mathrm{~V}_{2}\left(\mathrm{PO}_{4}\right)_{3}$, $\mathrm{Na}_{3} \mathrm{Cr}_{2}\left(\mathrm{PO}_{4}\right)_{3}$ and $\left.\mathrm{Na}_{3} \mathrm{Fe}_{2}\left(\mathrm{PO}_{4}\right)_{3}\right)$ as well at high temperature. The phase diagram is developed by grand canonical Monte-Carlo (GCMC) simulations based on a cluster expansion $(\mathrm{CE})$ model, ${ }^{48}$ which is built on density functional theory (DFT) ${ }^{49,50}$ calculations. Importantly, we find specific temperature and Na-concentration domains where the rhombohedral-NaSiCON exhibits a biphasic behavior (or phase separation), which is similar to the behavior observed in NaSiCON-based electrodes. Finally, we provide strategies for further optimizing the synthesis of NaSiCON-related materials and improving their ion-transport properties.

\section{Details of Monte Carlo, Cluster Expansion and DFT Calculations}

To coarse grain the Gibbs free-energy with changes in composition and temperature of the rhombohedral $\mathrm{Na}_{1+\mathrm{x}} \mathrm{Zr}_{2} \mathrm{Si}_{\mathrm{x}} \mathrm{P}_{3-\mathrm{x}} \mathrm{O}_{12}$, the Metropolis-Hasting GCMC $^{51}$ was performed using a CE Hamiltonian. The $\mathrm{CE}$ was parameterized on various Na-vacancy (Va) and $\mathrm{Si}-\mathrm{P}$ configurations, and the $\mathrm{CE}$ fit was obtained using the cluster assisted statistical mechanics (CASM) code $^{52-55}$ In performing the GCMC simulations, every $\mathrm{Na} / \mathrm{Va}$ swap must be coupled to a $\mathrm{Si} / \mathrm{P}$ swap or vice versa, in order to maintain the charge neutrality of the overall simulation cell. We have enforced the charge neutrality by modifying the GCMC code in the CASM package (https://github. com/caneparesearch/CASMcode). ${ }^{52-55}$ GCMC runs were performed on $16 \times 16 \times 16$ supercells of the primitive cell with 172,032 atoms and ranged between 57,344,000 and 573,440,000 steps. The condition of charge neutrality increases substantially the number of GCMC steps required to achieve convergence compared to GCMC simulations without this constraint. GCMC simulations were considered converged when deviations in formation energies reached $\leq 0.5 \mathrm{meV} /$ f.u.

In GCMC, either the chemical potential $(\mu)$ or temperature (T) can vary. Due to the charge- 
neutrality constraint, there is a single independent $\mu$ in the NaSiCON system, i.e., one unique composition variable $(x)$. As a result of the three ground-states in the convex hull at $\mathrm{x}=$ 0, 2 and 3 (see Section 3.1), $\mu$ was scanned in two regions with a fine step-size $(\Delta \mu=$ $0.005 \mathrm{eV} / \mathrm{f} . \mathrm{u})$ in both "forward" and "backward" directions (Section S4 in Supporting Information, SI). GCMC scans were also performed at fixed $\mu$ and with varying $\mathrm{T}$ from 5 to $1605 \mathrm{~K}$ $(\Delta \mathrm{T}=5 \mathrm{~K})$.

The CE Hamiltonian, based on the approach of Sanchez et al., ${ }^{48}$ parameterizes the formation energies $\left(E_{f}\right.$ in Eq. 2), as calculated from DFT, of various $\mathrm{Na} / \mathrm{Va}$ and $\mathrm{Si} / \mathrm{P}$ configurations, which are mapped onto a fixed $\mathrm{Na}_{4} \mathrm{Zr}_{2} \mathrm{Si}_{3} \mathrm{O}_{12}$ topology. The $\mathrm{CE}$ is typically written as a truncated summation of the Effective Cluster Interactions (ECIs) of pair, triplet, quadruplet, and higher order clusters as:

$$
E[\vec{\zeta}, \vec{\phi}]=V_{0}+V_{i} \zeta_{i}+V_{i j} \zeta_{i} \zeta_{j}+V_{i a} \zeta_{i} \phi_{a}+V_{a b} \phi_{a} \phi_{b}+\cdots .
$$

where $E[\vec{\zeta}, \vec{\phi}]$ is the formation energy of a $\mathrm{Na} / \mathrm{Va}$ and $\mathrm{Si} / \mathrm{P}$ configuration (i.e., a given structure). The ECI $V$, and a polynomial function mapping the occupation of the lattice site, with $\zeta_{i}=0$ or 1 representing the occupation of $\mathrm{Na}$ or Va and $\phi_{a}=0$ or 1 that of Si or P. ${ }^{56}$ Each ECI in the sum includes the multiplicity (the cluster symmetry). All symmetrically distinct pairs, triplets, and quadruplets in the rhombohedral cell within a radius of $10 \AA, 6 \AA$ and $5 \AA$, respectively, are used for constructing the $\mathrm{CE}$ model. Note that including larger clusters via increasing the maximum radius (within which clusters are included) results in a dramatic increase of the basis-set size and the complexity of the fitting procedure, without any improvement in the quality of the CE.

Different Na compositions of the rhombohedral$\mathrm{NaSiCON}$ were studied by varying the $\mathrm{Na}$ content from $\mathrm{Na}_{4} \mathrm{Zr}_{2} \mathrm{Si}_{3} \mathrm{O}_{12}$ to $\mathrm{Na}_{1} \mathrm{Zr}_{2} \mathrm{P}_{3} \mathrm{O}_{12}$. To keep charge neutrality in $\mathrm{Na}_{4} \mathrm{Zr}_{2} \mathrm{Si}_{3} \mathrm{O}_{12}$ upon the "removal" of $\mathrm{Na}^{+}$ions (i.e., addition of vacancies), the $\mathrm{Si}^{4+}$ ions must also be substituted by $\mathrm{P}^{5+}$ ions. Hence, we used the so-called "coupled" CE model ${ }^{57}$ that constraints the concentration of $\mathrm{Si}^{4+} / \mathrm{P}^{5+}$ to $\mathrm{Na}^{+} / \mathrm{Va}$ by utilizing a single "point" term $\left(\zeta_{i}\right)$ of Eq. 1. The point term in a CE typically sets $\mu$ and the presence of a single $\mu$ ensures charge neutrality of the underlying NaSiCON within the CE. Given the large number of clusters available versus the number of DFT-calculated configurations, we used the compressive sensing approach to determine the absolute values of the ECIs by employing $\alpha=1.5 \times 10^{-5}$ to penalize the L1-norm of the ECIs and minimize overfitting. ${ }^{58}$

Different $\mathrm{Na} / \mathrm{Va}$ and $\mathrm{Si} / \mathrm{P}$ configurations were enumerated using the pymatgen package. ${ }^{59}$ The primitive cell of the experimental rhombohedral $\mathrm{Na}_{4} \mathrm{Zr}_{2} \mathrm{Si}_{3} \mathrm{O}_{12}$ structure ${ }^{60}$ (2 f.u., with 42 atoms) was used to enumerate the configurations in the possible $\mathrm{Na}$ concentration range $(0 \leq x \leq 3)$ at a step-size, $\Delta x=0.5$. To keep the number of possible configurations to a computationally tractable level, we used an electrostatic ranking scheme based on the Ewald energy, ${ }^{61}$ where classical point charges are assigned to each species $(\mathrm{Na}=+1, \mathrm{Zr}=+4$, $\mathrm{Si}=+4, \mathrm{P}=+5$, and $\mathrm{O}=-2)$. We selected 500 symmetrically distinct structures at each $x$ with the lowest Ewald energies. Additionally, we applied a similar enumeration and ranking procedure to obtain $\mathrm{Na} / \mathrm{Va}$ and $\mathrm{Si} / \mathrm{P}$ configurations in $2 \times 1 \times 1$ supercells ( 4 f.u., with 84 atoms, equivalent to $1 \times 2 \times 1$ and $1 \times 1 \times 2)$ of the primitive cell with a step-size, $\Delta x=0.25$. In total, we computed 1192 structurally distinct orderings using DFT as implemented in VASP. ${ }^{62,63}$

The exchange-correlation energy in DFT was approximated by the strongly constrained and appropriately normed (SCAN) semi-local metageneralized gradient approximation (GGA) functional. ${ }^{64}$ The accuracy of SCAN has been demonstrated on oxides and phosphates, ${ }^{65-67}$ where SCAN has been shown not to overbind $\mathrm{O}_{2}$ gas, as is typical in GGA functionals. ${ }^{68}$ Wavefunctions were expanded in terms of a plane-wave basis set, truncated at a kinetic energy cut-off of $520 \mathrm{eV}$ and combined with projector augmented-wave (PAW) potentials to describe the core electrons. ${ }^{69}$ The PAW potentials used were $\mathrm{Na}$ _pv 19Sep2006 $2 p^{6} 3 s^{1}$, $\mathrm{Zr}$ _sv 04Jan2005 $4 s^{2} 4 \bar{p}^{6} 4 d^{2} 5 s^{2}$, Si 05Jan2001 $3 s^{\overline{2}} 3 p^{2}$, P 06Sep2000 $3 s^{2} 3 p^{3}$ and O 08Apr2002 $2 s^{2} 2 p^{4}$. Total energies were integrated on a 
$3 \times 3 \times 3$ Monkhorst-Pack grid ${ }^{70}$ for the primitive cells (while the $k$-point density was maintained for the larger supercells), and converged within $10^{-5} \mathrm{eV} /$ cell, without preserving any symmetry. The atomic forces (and stresses) were converged to within $10^{-2} \mathrm{eV} / \AA(0.29 \mathrm{GPa})$.

\section{Results}

\subsection{The Energetics of the $\mathrm{Na}$ and $\mathrm{Si} / \mathrm{P}$ Configurations in the Rhombohedral-NaSICON}

The formation energy $\left(E_{f}\right)$ of each ordering, computed by DFT, is defined with respect to the lowest energy end-member compositions, $\mathrm{Na}_{4} \mathrm{Zr}_{2} \mathrm{Si}_{3} \mathrm{O}_{12}$ and $\mathrm{Na}_{1} \mathrm{Zr}_{2} \mathrm{P}_{3} \mathrm{O}_{12}$, using Eq. 2

$$
\begin{aligned}
E_{f} & =E\left[\mathrm{Na}_{1+\mathrm{x}} \mathrm{Zr}_{2} \mathrm{Si}_{\mathrm{x}} \mathrm{P}_{3-\mathrm{x}} \mathrm{O}_{12}\right]- \\
& +\frac{x}{3} E\left[\mathrm{Na}_{4} \mathrm{Zr}_{2} \mathrm{Si}_{3} \mathrm{O}_{12}\right]-\left(1-\frac{x}{3}\right) E\left[\mathrm{Na}_{1} \mathrm{Zr}_{2} \mathrm{P}_{3} \mathrm{O}_{12}\right] .(2)
\end{aligned}
$$

where $E\left[\mathrm{Na}_{1+\mathrm{x}} \mathrm{Zr}_{2} \mathrm{Si}_{\mathrm{x}} \mathrm{P}_{3-\mathrm{x}} \mathrm{O}_{12}\right], E\left[\mathrm{Na}_{4} \mathrm{Zr}_{2} \mathrm{Si}_{3} \mathrm{O}_{12}\right]$ and $E\left[\mathrm{Na}_{1} \mathrm{Zr}_{2} \mathrm{P}_{3} \mathrm{O}_{12}\right]$ are the DFT total energies of each $\mathrm{Na} / \mathrm{Va}+\mathrm{Si} / \mathrm{P}$ ordering, and the two end-members. Figure 2 plots the formation energy vs. Na composition, which is the phase diagram of the rhombohedral-NaSiCON system at $0 \mathrm{~K}$. The DFT formation energies are shown in yellow whereas the formation energies predicted by the CE model are shown in blue (Figure 2a). The convex envelopes of the structures with the lowest formation energies -the convex hull- as predicted by DFT and $\mathrm{CE}$ are depicted by solid yellow and solid blue lines, respectively. Importantly, the three lowest energy (or ground state) configurations that lie on both the DFT and CE hulls occur at $\mathrm{Na}$ compositions of $x=0.0,2.0$, and 3.0 , in agreement with experimental observations. ${ }^{29,71}$ Thus, there should be a distinct, stable $\mathrm{Na} / \mathrm{Va}$ (and $\mathrm{Si} / \mathrm{P}$ ) ordering corresponding to the $x=2.0$ ground state configuration, apart from the $x=0.0$ and $x=3.0$ end-members.

Note that the ground state at $\mathrm{Na}_{3} \mathrm{Zr}_{2} \mathrm{Si}_{2} \mathrm{P}_{1} \mathrm{O}_{12}$ $(x=2.0)$ distorts away from rhombohedral symmetry upon DFT structure relaxation, which indicates the tendency for the rhombohedral-NaSiCON to transform into the stable low-temperature monoclinicNaSiCON. ${ }^{29,37,72,73}$ In Figure 2a, most orderings in $2 \times 1 \times 1$ supercells exhibit higher formation energies than configurations within the primitive cell. For example, all the configurations that exhibit $E_{f}<-50 \mathrm{meV} /$ f.u. at $x=0.5,1.0,1.5,2.0$ and 2.5 are orderings within the primitive cell.

\subsection{The Cluster Expansion Model}

Of the 1192 distinct orderings computed by DFT (Figure 2a), only 884 configurations were selected to fit the CE model Hamiltonian. The reduction of our data set is due to the high (and expected) mobility of $\mathrm{Na}$ ions in specific starting configurations, which causes $\mathrm{Na}$ ions to move from their initial positions during the structure relaxation to final positions that are symmetrically equivalent to other initial $\mathrm{Na}$ configurations. We removed selected high energy structures, primarily at $x=0$ and 0.25 , that undergo appreciable distortion upon geometry relaxation with DFT. The ECIs obtained via fitting the $\mathrm{CE}$ to the DFT formation energies are depicted in Figure 3.

The ECIs of Figure 3 are obtained by minimizing the root mean square error (RMSE) against the DFT energies of all 884 configurations, which is $\sim 11.20 \mathrm{meV} /$ f.u. $\quad(\sim 0.53$ $\mathrm{meV} /$ atom), while minimizing the total magnitude of all ECIs to minimize overfitting. ${ }^{58}$ The transferability of the $\mathrm{CE}$ is assessed via the leave one-out cross-validation (LOOCV) score, which is $\sim 24.9 \mathrm{meV} /$ f.u. (1.18 meV/atom). The 65 clusters with non-zero ECIs are listed in Table $\mathrm{S} 2$ of the SI.

Of the 65 ECIs, 38 ECIs are pair interactions, 22 are triplets and 4 are quadruplets. In Figure 3, a negative ECI indicates "attractive" interactions between Va for clusters built on $\mathrm{Na} / \mathrm{Va}$ sites and $\mathrm{P}$ for clusters consisting of $\mathrm{Si} / \mathrm{P}$ sites. Since the NaSiCON structure has both $\mathrm{Na} / \mathrm{Va}$ and $\mathrm{Si} / \mathrm{P}$ sites, attractive interactions are also extended to other species with the same occupational variable. Specifically, our CE model uses an identical notation for the occupation of $\mathrm{Na} / \mathrm{Si}(\sigma=0)$ and $\mathrm{Va} / \mathrm{P}(\sigma=+1)$. Thus, a negative ECI on a 

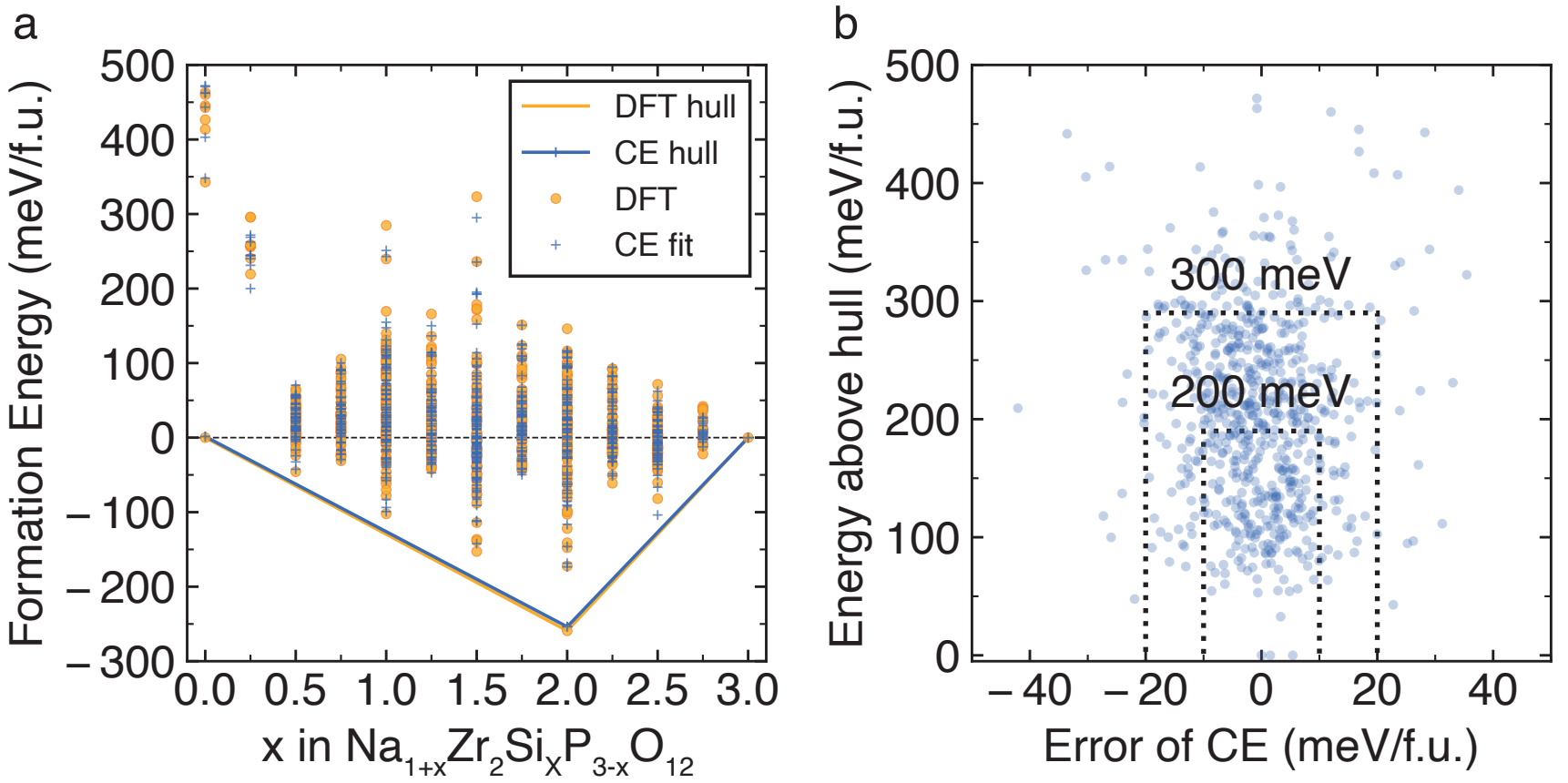

Figure 2: Formation energy of the rhombohedral-NaSICON vs. Na/Va (x) and $\mathrm{Si} / \mathrm{P}$ $(3-x)$ composition (panel a). Yellow dots are the formation energies from DFT, while blue crosses depict the energies from the cluster expansion model. The DFT and CE convex hulls are shown by solid yellow and blue lines. Panel b plots the error of the CE model with respect to DFT (horizontal axis) vs. the energy above the convex hull (vertical axis). The dashed lines in $b$ are confidence windows (of \pm 10 and $\pm 20 \mathrm{meV} / \mathrm{f} . \mathrm{u}$ ) for the CE model.

$\mathrm{Na} / \mathrm{Va}-\mathrm{Si} / \mathrm{P}$ pair translates to an attractive interaction that favors the occupation of $\mathrm{Va}$ (on the $\mathrm{Na} / \mathrm{Va}$ site) and $\mathrm{P}$ (on the $\mathrm{Si} / \mathrm{P}$ site). Similarly, positive ECIs indicate "repulsive" interactions between Va and P. Due to the specific assignment of $\sigma=0$ for any $\mathrm{Na} / \mathrm{Si}$ occupation, only clusters that are fully constituted by Va and/or by $\mathrm{P}$ contribute to non-zero ECIs towards the overall energy estimation in our CE model. The dominant pair and triplet terms in Figure 3, i.e., highest absolute magnitude ECI, are the repulsive pair cluster \#34 (Na/Va$\mathrm{Na} / \mathrm{Va}$ of length $\sim 7.40 \AA)$, the attractive pair cluster \#65 (Na/Va-Na/Va, $9.19 \AA)$, and the triplet cluster $\# 92(\mathrm{Na} / \mathrm{Va}-\mathrm{Na} / \mathrm{Va}-\mathrm{Na} / \mathrm{Va}$, $\sim 4.72 \AA$ ), respectively. All dominant pair, triplet and quadruplet interactions within our CE model are listed in Tables S3, S4 and S5 of the SI.

Remarkably, our CE model captures some important physics of the system. For example, the attractive pair \#6 (in Figure S1 of the SI) fa- vors Va located within the cluster formed by one $\mathrm{Na}(1)$ and one $\mathrm{Na}(2)$ site, separated by a length $\sim 3.162 \AA$ within the primitive rhombohedral cell. However, a larger $(\sim 6.52 \AA)$ pair cluster \#27 (in Figure S1 of the SI) with $\mathrm{Na}(1)$ and $\mathrm{Na}(2)$ sites is repulsive, which favors either a Na-Va or a Na-Na occupation within the pair. Thus, the interplay between pair \#6 and \#27 indicates the competition between short-range vs. long-range ordering phenomena in the structure. Furthermore, the most dominant triplet is ECI \#92, is repulsive, penalizes the Va-VaVa occupation and consists of one $\mathrm{Na}(1)$ and two $\mathrm{Na}(2)$ sites within the primitive cell (size $<4.73 \AA$ ), see Table S1 in SI. Hence, ECI \#92 captures the rather strong short-range interaction between symmetrically distinct $\mathrm{Na}$ sites, i.e., $\mathrm{Na}(1)$ and $\mathrm{Na}(2)$ (as elucidated in Section 3.5). Also, the triplet ECI \#92 likely acts in conjunction with pairs \#27 and \#6 (both involving $\mathrm{Na}(1)$ and $\mathrm{Na}(2)$ sites) to favour a Va-Na-Na configuration on the $\mathrm{Na}(1)-\mathrm{Na}(2)-$ 


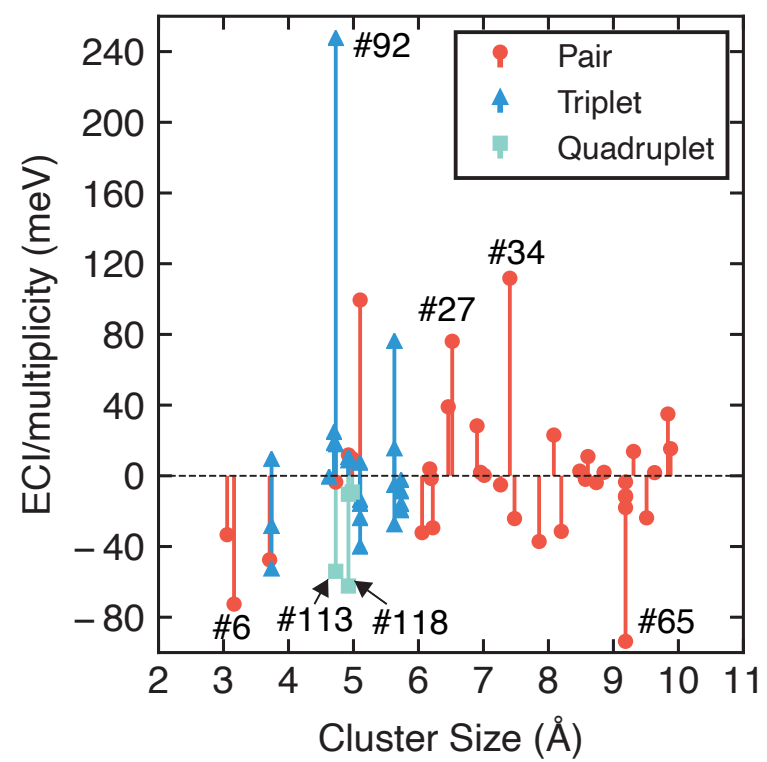

Figure 3: Plot of the 65 ECI values (in $\mathrm{meV} /$ multiplicity, vertical axis) of each cluster vs. their size (in $\AA$, horizontal axis). Negative (positive) ECIs in pairs are attractive (repulsive) interactions between Va-Va, P-P, and Va-P. The indexes of specific ECIs are indicated (Table S2 in SI).

$\mathrm{Na}(2)$ sites, which is the underlying motif of the ground state at $x=2$ at $0 \mathrm{~K}$ (see Figure $\mathbf{2} \mathbf{a}$ and Section 3.5). Finally, the quadruplet ECIs \#113 and \#118 are attractive, span across $\mathrm{Na} / \mathrm{Va}$ and $\mathrm{Si} / \mathrm{P}$ sites, and favour occupations of Va-Va-Va-P and Va-Va-P-P, respectively, which likely indicate the electrostatic attraction between $\mathrm{Va}$ and $\mathrm{P}$ species.

The error in formation energies predicted by the CE expansion model are compared with the energy above the convex hull in Figure 2b, with two regions of confidences, \pm 10 and $\pm 20 \mathrm{eV} /$ f.u. (dashed lines). Importantly, the CE reproduces well the DFT formation energies within $\sim 100 \mathrm{meV} /$ f.u. above the convex hull line. In Figure $2 \mathbf{b}$, points near $0 \mathrm{meV} /$ f.u. on the horizontal axis represent a perfect fit with the DFT data, whereas points beyond $\pm 20 \mathrm{meV} /$ f.u. can be considered poorly described by the model. Most of the formation energies predicted by the $\mathrm{CE}$ model lie within the $\pm 20 \mathrm{meV} /$ f.u. window, which indicates that the $\mathrm{CE}$ can also reproduce the formation energies of several high energy configurations accurately.

\subsection{Temperature-Composition Phase Diagram of the Rhom- bohedral $\mathrm{Na}_{1+\mathrm{x}} \mathrm{Zr}_{2} \mathrm{Si}_{\mathrm{x}} \mathrm{P}_{3-\mathrm{x}} \mathrm{O}_{12}$}

Using large simulation cells (172,032 atoms) with GCMC, we can coarse-grain ${ }^{74}$ the grandcanonical potential at any $\mathrm{Na}(\mathrm{Va}) / \mathrm{Si}(\mathrm{P})$ concentration and temperature. The temperature vs. Na-composition phase diagram, as obtained via GCMC simulations, is shown in Figure 4. The phase boundaries of Figure 4 are identified by analyzing the grand-canonical potential energies, the discontinuities of $\mathrm{Na}$ concentration (vs. $\mu$ ), and the variation of the heat capacity (vs. $\mu$ ). Numerical hysteresis arising from the GCMC was removed by performing a freeenergy integration (see Section S4 and Figure $\mathrm{S} 2$ of the SI). ${ }^{74} \mathrm{~A}$ representative snapshot of GCMC simulations is provided in Figure S3.

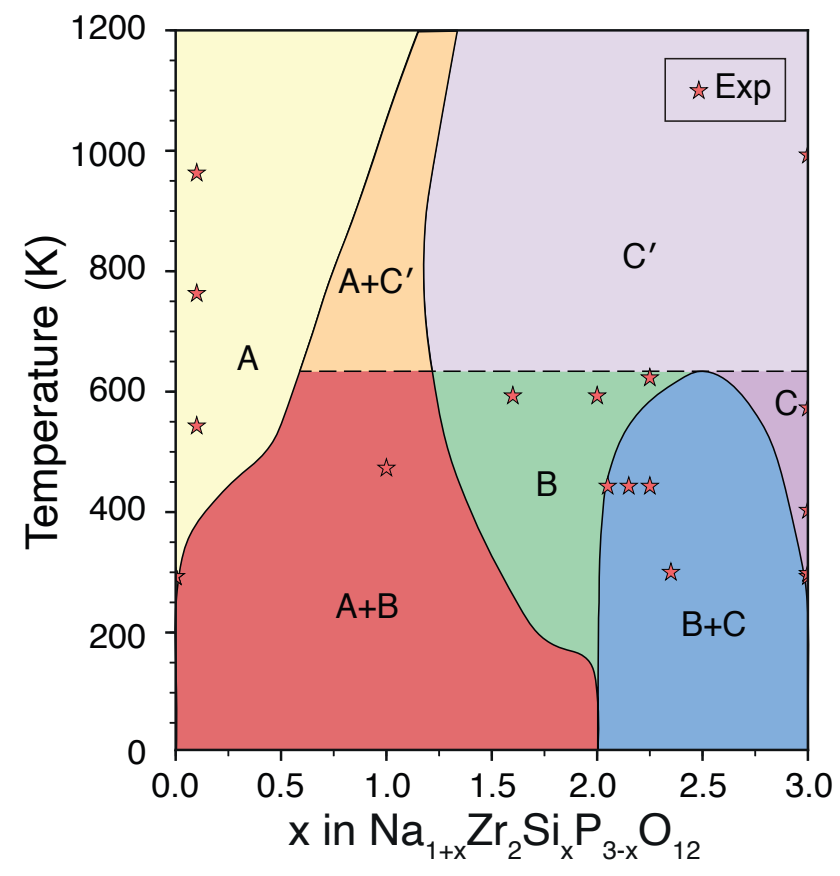

Figure 4: Predicted composition (horizontal axis) vs. temperature (vertical axis) phase diagram of rhombohedral$\mathrm{Na}_{1+\mathrm{x}} \mathrm{Zr}_{2} \mathrm{Si}_{\mathrm{x}} \mathrm{P}_{3-\mathrm{x}} \mathrm{O}_{12}$ from GCMC simulations. Red stars indicates diffraction studies of rhombohedral-NaSiCON reported experimentally. ${ }^{33,40,60,75-79}$ 
The phase diagram in Figure 4 contains four single-phase (or monophasic) regions, which are labelled as A (yellow), B (green) C (dark purple) and C' (light purple), with three twophase (or biphasic) regions separating the monophasic domains. The biphasic regions are $\mathrm{A}+\mathrm{B}$ (red dome between $0<x<2$, $T<650 \mathrm{~K}$ ), A+C' (orange dome, $T>650 \mathrm{~K}$ ), and $\mathrm{B}+\mathrm{C}$ (blue dome between $2<x<3$ ). The monophasic regions can be described as, A: Na-poor domain, similar to the rhombohedral$\mathrm{Na}_{1} \mathrm{Zr}_{2} \mathrm{P}_{3} \mathrm{O}_{12} ; \mathrm{C}$ : Na-rich domain, similar to $\mathrm{Na}_{4} \mathrm{Zr}_{2} \mathrm{Si}_{3} \mathrm{O}_{12} ; \quad \mathrm{B}$ : high-conductivity domain based on the $\mathrm{Na}_{3} \mathrm{Zr}_{2} \mathrm{Si}_{2} \mathrm{P}_{1} \mathrm{O}_{12}$ configuration, which is the target composition in experimental studies; and C': a high-temperature disordered domain that encompasses both $\mathrm{Na}_{3} \mathrm{Zr}_{2} \mathrm{Si}_{2} \mathrm{P}_{1} \mathrm{O}_{12}$ and $\mathrm{Na}_{4} \mathrm{Zr}_{2} \mathrm{Si}_{3} \mathrm{O}_{12}$ regions. Experimentally the $\mathrm{Na} / \mathrm{Va}$ and $\mathrm{Si} / \mathrm{P}$ lattices in rhombohedralNaSiCON are known to disorder in the composition range $1<x<3$ (i.e., excluding the end members) and at high temperatures $(>473 \mathrm{~K}),{ }^{9,32,33,33,72,80}$ in qualitative agreement with our predicted phase diagram.

In the case of the B-phase (green domain in Figure 4), at temperatures $<150 \mathrm{~K}$, phase B is only stable at near $x=2$, but its stable composition range increases progressively with increasing temperature to a maximum range of $1.25 \leq x \leq 2.5$ at $650 \mathrm{~K}$. The region of stability of the B-phase also overlaps with the composition $(1.8 \leq x \leq 2.2)$ and temperature $(<415 \mathrm{~K})$ where the rhombohedral structure transforms into the monoclinic polymorph in experiments. ${ }^{29,30,72}$ Thus, the presence of the B-phase may facilitate the rhombohedral-tomonoclinic transition. At temperatures above $650 \mathrm{~K}$, a high-temperature disordered phase C' appears, which encompasses both the $\mathrm{B}$ and $\mathrm{C}$ monophasic regions. The miscibility gap that separates the $\mathrm{B}$ and $\mathrm{C}$ monophasic regions (blue dome in Figure 4), reaches its critical point at $x=2.5$ and $650 \mathrm{~K}$. The transition from the high-temperature disordered C' phase to the miscibility gap (i.e., the $\mathrm{B}+\mathrm{C}$ two phase region) represents a first-order phase transition, and marked by the dashed black line at $650 \mathrm{~K}$.

The experimental compositions, which are assigned to single-phase regions and deter- mined from X-ray and neutron diffraction measurements, are shown as red stars in Figure 4. ${ }^{40,60,72,75-79}$ Most experimentally observed compositions are found in the single phase regions of $\mathrm{A}, \mathrm{B}, \mathrm{C}$ or $\mathrm{C}$ ', and in good agreement with our calculated phase diagram. Exceptions are reported single-phase structures at $x=2 .-2.3$ at $443 \mathrm{~K}, x=0.1$ and 2.35 at $300 \mathrm{~K},{ }^{33}$ and $x=1$ at $473 \mathrm{~K} .{ }^{40}$ Although most of the disagreements with experimentally reported single-phase compositions lie at (or near) the predicted phase boundaries, the measured, low temperature data point at $x=2.35$, $300 \mathrm{~K}$ significantly deviates from our predictions. Notably, the experimental literature, so far, on $\mathrm{Na}_{1+\mathrm{x}} \mathrm{Zr}_{2} \mathrm{Si}_{\mathrm{x}} \mathrm{P}_{3-\mathrm{x}} \mathrm{O}_{12}$ has never reported any phase separation in this system.

\subsection{Na/Vacancies and $\mathrm{Si} / \mathrm{P}$ Con- figurational Effects on the Structural Properties}

The DFT-calculated volumes (panel a) and lattice constants $a$ and $c$ (panel $\mathbf{b}$ ) of the various configurations as a function of the Na composition are shown in Figure 5. Stars represent experimentally reported values of volumes, lattice constants and $c / a$ ratio, ${ }^{29,32,33,60,75-80}$ while dots, squares and triangles are the DFTpredicted values. The color of each point in Figure 5 is associated with its energy above the convex hull (Figure 2a), with darker blue (lighter white) indicating structures that are near (far away from) the convex hull. The black-dashed lines connect volumes, lattice constants and $c / a$ ratio of structures forming the convex hull. ${ }^{29,32,33,43,81}$

Moving from $x=0$ to $x=2$ in Figure $5 \mathbf{a}$, the predicted volume increases monotonically with a maximum at $x=2\left(\mathrm{Na}_{3} \mathrm{Zr}_{2} \mathrm{Si}_{2} \mathrm{P}_{1} \mathrm{O}_{12}\right)$, in excellent agreement with experimental reports (distribution of stars). Although DFT calculations do not capture the effect of temperature, the agreement between theory and experiments on lattice volumes can be attributed to the low thermal expansion $\left(<5 \%, 11.8 \times 10^{-6}\right.$ ${ }^{\circ} \mathrm{C}^{-1}$ ) with increasing temperature (over a wide temperature range, i.e., $25<\mathrm{T}<700{ }^{\circ} \mathrm{C}$ ) of 

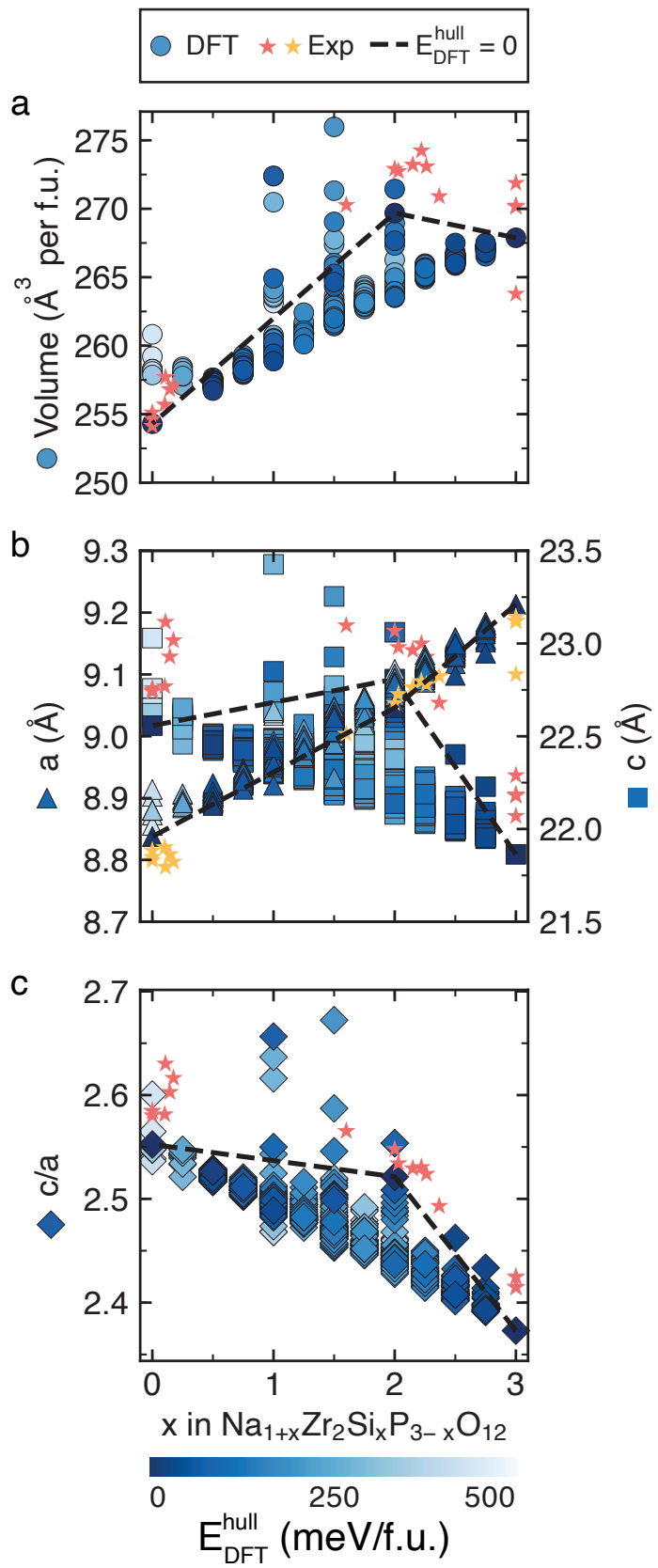

Figure 5: DFT-calculated volumes (vertical axis) in panel a and lattice constants $a$ and $c$ in panel $\mathbf{b}$ of rhombohedralNaSiCON vs. composition $x$ (horizontal axis). In panel $\mathrm{c}$ the $c / a$ ratio is shown. Each dot, square or triangle is colored according to its energy above the convex hull. Dashed black line connects ground state configurations that are on the convex hull at $0 \mathrm{~K}$. Experimentally reported volumes and lattice constants $^{29,32,33,60,75-80}$ at specific concentrations are indicated by starts.
NaSiCON. ${ }^{60,75}$ In the case of lattice parameters (Figure $5 \mathbf{b}$ ), we observe that the $a$ parameter increases monotonically with increasing $\mathrm{Na}$ content, while the $c$ parameter increases for $0<x<2$ and decreases for $x>2$, in excellent agreement with experimental studies. ${ }^{29,33} \mathrm{As}$ the Na content increases in $\mathrm{Na}_{1+\mathrm{x}} \mathrm{Zr}_{2} \mathrm{Si}_{\mathrm{x}} \mathrm{P}_{3-\mathrm{x}} \mathrm{O}_{12}$ in the range $0<x<2$, the $\mathrm{Na}^{+}$are displaced from $\mathrm{Na}(1)$ into $\mathrm{Na}(2)$ sites (Figure 6d, e and f). The reduced occupation of $\mathrm{Na}(1)$ sites facilitates the electrostatic repulsion between $\mathrm{ZrO}_{6}$ units stacked along the $c$ direction, resulting in an increase in the $c$ parameter.

Importantly, we predict a mild volume contraction $(\sim 1 \%$, panel a) for $x>2$, in agreement with experimental observations that $\mathrm{Na}_{4} \mathrm{Zr}_{2} \mathrm{Si}_{3} \mathrm{O}_{12}$ has a lower volume than $\mathrm{Na}_{3} \mathrm{Zr}_{2} \mathrm{Si}_{2} \mathrm{P}_{1} \mathrm{O}_{12}(\sim 1 \%$ smaller $)$ due to a contraction of the $c$ axis (panel b). ${ }^{75}$ The reduction of the $c / a$ ratio with increasing $\mathrm{Na}$ concentration (Figure 5c) captures the typical behavior of the rhombohedral-NaSiCON as the Na content is varied (stars in panel c).

\subsection{Thermodynamic Properties and Na occupations vs. Tem- perature}

The GCMC data enable the analysis of relevant thermodynamic properties, e.g., the Gibbs energy ( $G$, orange dots and lines) and the configurational entropy ( $S$, green dots and lines) functions. These are shown in Figure 6, for 3 distinct temperatures, a $445 \mathrm{~K}$, b $625 \mathrm{~K}$, and c $905 \mathrm{~K}$ centered around the $\mathrm{B}+\mathrm{C} \rightarrow \mathrm{C}$ ' transition $(\sim 650 \mathrm{~K})$. Note that the Gibbs energies are referenced to the ground state endmember configurations, namely $\mathrm{Na}_{1} \mathrm{Zr}_{2} \mathrm{P}_{3} \mathrm{O}_{12}$ and $\mathrm{Na}_{4} \mathrm{Zr}_{2} \mathrm{Si}_{3} \mathrm{O}_{12}$. Panels d-f in Figure 6 show the extent of occupation of $\mathrm{Na}(1)$ (blue dots and lines) and $\mathrm{Na}(2)$ (red dots and lines) by $\mathrm{Na}^{+}$ vs. $x$ at three temperatures, where a fully Naoccupied site (fully empty) has an occupancy of $1.0(0.0)$. Notably, the occupation values are obtained as statistical averages from GCMC simulations. Also, the multiplicity of $\mathrm{Na}(2)$ is three times that of $\mathrm{Na}(1)$, i.e., there are three $\mathrm{Na}(2)$ sites for every $\mathrm{Na}(1)$. Dashed lines in 
all panels of Figure 6 indicate thermodynamic properties and $\mathrm{Na}$ occupancies within biphasic regions.

An increasing temperature typically decreases $G$, which is consistent with the more negative Gibbs energies at $905 \mathrm{~K}$ compared to $445 \mathrm{~K}$ in Figure 6. While $S$ depends strongly on the temperature, the value of $S$ at a given $x$ depends on the number of accessible configurations at that composition. For example, $S(x=3)=0$ at all temperatures since there are no configurational degrees of freedom available at the $\mathrm{Na}_{4} \mathrm{Zr}_{2} \mathrm{Si}_{3} \mathrm{O}_{12}$ composition, i.e., no configurations lie above the convex hull at this composition (Figure 2).

Below the $\mathrm{B}+\mathrm{C} \rightarrow \mathrm{C}$ ' transition (445 and $625 \mathrm{~K}), S(x)$ shows three distinct segments for the three monophasic regions $\mathrm{A}, \mathrm{B}$ and $\mathrm{C}$, with three minima of $S(x)$ (and $G(x)$ ) located at the $0 \mathrm{~K}$ ground state compositions, namely, $x=0$, 2 , and 3. The higher entropy observed for other compositions away from the $0 \mathrm{~K}$ ground states is indicative of the higher configurational disorder within the $\mathrm{Na} / \mathrm{Va}$ and $\mathrm{Si} / \mathrm{P}$ sub-lattices. Importantly, the minima in entropy at $\mathrm{x} \sim 2$ (within the $\mathrm{B}$ monophasic region) at $625 \mathrm{~K}$ and $445 \mathrm{~K}$ correlates with the Na occupancies of the $\mathrm{Na}(1)$ and $\mathrm{Na}(2)$ sites (Figures 6d-f, see discussion below). At $905 \mathrm{~K}$ (beyond the $\mathrm{B}+\mathrm{C} \rightarrow \mathrm{C}$ ' transition), $S(x)$ shows two distinct segments, corresponding to the A and C' monophasic region.

Unraveling the distribution of $\mathrm{Na}$ among the $\mathrm{Na}(1)$ and $\mathrm{Na}(2)$ sites can shed light on the Na-ion transport in NaSiCON phases, which is still not fully understood. ${ }^{37}$ From Figures 6 d-f, we note that for $x=0, \mathrm{Na}(1)$ is fully occupied and $\mathrm{Na}(2)$ is empty at all temperatures, in agreement with previous reports indicating that $\mathrm{Na}_{1} \mathrm{Zr}_{2} \mathrm{P}_{3} \mathrm{O}_{12}$ is a fully ordered phase, with $\mathrm{Na}$ occupying only $\mathrm{Na}(1) .{ }^{71,75}$ Similarly, at $x=3$, both $\mathrm{Na}(1)$ and $\mathrm{Na}(2)$ sites are fully occupied, in agreement with the observations of Hong et al. ${ }^{29}$ Interestingly, within the monophasic A region $(\mathrm{x}=0$ to $\mathrm{x} \sim 1)$ at $905 \mathrm{~K}$, the occupation of $\mathrm{Na}(2)$ increases with increasing $\mathrm{x}$, while $\mathrm{Na}(1)$ remains fully occupied (Figure 6f). At higher sodium contents, i.e., $x>2$ (within $\mathrm{C}^{\prime}$ ), the occupation of $\mathrm{Na}(1)$ increases monotonically to- wards 1.0 at $x=3$, while the occupation of $\mathrm{Na}(2)$ remains roughly constant $(\sim 1.0)$. However, at intermediate $\mathrm{Na}$ contents $(\mathrm{x} \sim 1.25$ to $\mathrm{x} \sim 1.75)$, the occupancies of $\mathrm{Na}(2)$ and $\mathrm{Na}(1)$ show contrasting trends with increasing $\mathrm{Na}$ content, i.e., as $\mathrm{Na}(2)$ sites are occupied by $\mathrm{Na}$, $\mathrm{Na}(1)$ sites become unoccupied. This simultaneous occupation and un-occupation of $\mathrm{Na}(2)$ and $\mathrm{Na}(1)$ sites results in a decrease of configurational entropy (Figure 6c), which eventually reaches a minima at $\mathrm{x} \sim 1.75$.

Similar trends in $\mathrm{Na}(1)$ and $\mathrm{Na}(2)$ occupancies at intermediate $\mathrm{Na}$ concentrations can also be observed below the $\mathrm{B}+\mathrm{C} \rightarrow \mathrm{C}^{\prime}$ transition (panels $\mathbf{d}$ and $\mathbf{e}$ in Figure 6), in agreement with the trends reported by Boilot and Collin (starts in panels $\mathbf{d}$ and e) ${ }^{33}$ Notably, the $\mathrm{Na}(1)$ sites become empty at $\mathrm{Na}$ compositions of $1.5<x<2$ within the B domain (at $445 \mathrm{~K}$ and $625 \mathrm{~K}$ ), whereas the $\mathrm{Na}(1)$ site is never fully empty in C' with the minimum in occupation reaching at $x \sim 1.75$. Also, the $\mathrm{Na}$ sites are completely ordered, i.e., $\mathrm{Na}(2)$ is fully occupied and $\mathrm{Na}(1)$ is fully empty, at $x=2$ within the B-phase, whereas complete ordering does not occur at $x=2$ within the high-temperature C' phase, underlying the key difference between the B and C' monophasic regions. Thus, Na occupying the $\mathrm{Na}(1)$ sites is the primary mechanism of inducing configurational disorder in the NaSiCON structure as the system transitions from ordered B to disordered C', particularly at $x=2$. Additionally, the complete ordering at $x=2$ in $\mathrm{B}$ corresponds to the minima in entropy observed at $445 \mathrm{~K}$ and $625 \mathrm{~K}$ at $x=2$ (Figure 6a-b).

\section{Discussion}

\subsection{Reconciling the Phase Behav- ior in NaSiCON-based Elec- trolytes and Electrodes}

Understanding the thermodynamic properties of the rhombohedral- $\mathrm{Na}_{1+\mathrm{x}} \mathrm{Zr}_{2} \mathrm{Si}_{\mathrm{x}} \mathrm{P}_{3-\mathrm{x}} \mathrm{O}_{12}$, and NaSiCON systems in general, is of importance for the development of inexpensive solid electrolytes and electrode materi- 

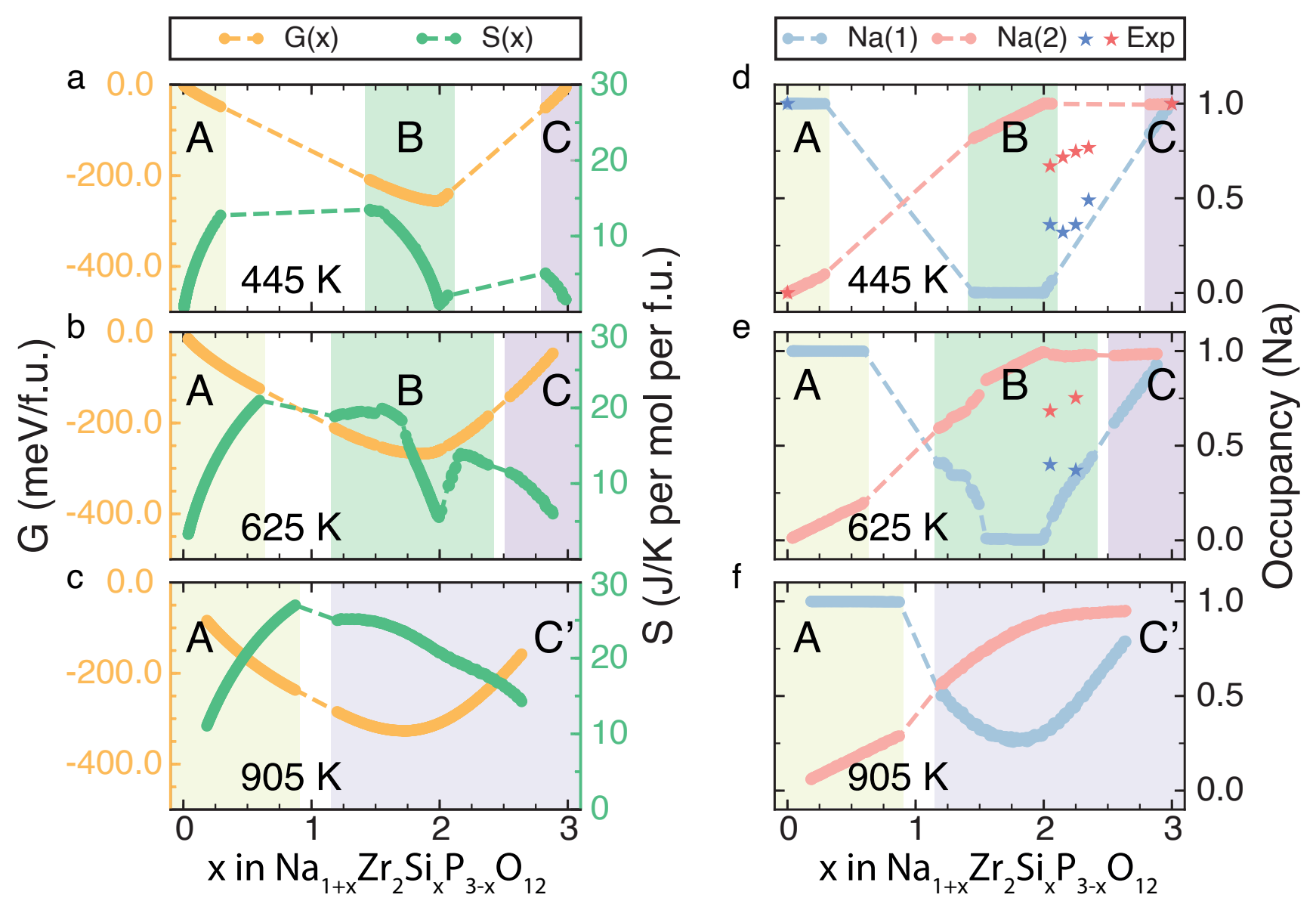

Figure 6: Thermodynamic properties (left panels, a, b and c) and Na occupancy (right panels, $\mathrm{d}$, e, and $\mathrm{f}$ ) are shown as a function of $\mathrm{Na}$ composition ( $\mathrm{x}$, horizontal axis). Gibbs free energy $G(x)$ (orange, left vertical axis) and configurational entropy $S(x)$ (in green, right vertical axis) are shown at specific temperatures $445 \mathrm{~K}$ (panel a), $625 \mathrm{~K}$ (panel b) and $905 \mathrm{~K}$ (panel c), respectively. Similarly, panels $\mathrm{d}$, e, and f display the distribution of $\mathrm{Na}$ between the two sites, $\mathrm{Na}(1)$ (in blue) and $\mathrm{Na}$ (2) (in red), at $445 \mathrm{~K}$, $625 \mathrm{~K}$ and $905 \mathrm{~K}$, respectively. Experimental data at $443 \mathrm{~K}$ and $623 \mathrm{~K}$ from Ref. 33 are indicated as blue/red stars for $\mathrm{Na}(1) / \mathrm{Na}(2)$ sites. Dashed lines indicate regions of phase separation in the phase diagram, while monophasic domains are shown by colored regions (from Figure 4).

als for novel Na-ion batteries. We have systematically analyzed the phase-diagram of rhombohedral- $\mathrm{Na}_{1+\mathrm{x}} \mathrm{Zr}_{2} \mathrm{Si}_{\mathrm{x}} \mathrm{P}_{3-\mathrm{x}} \mathrm{O}_{12}$ by combining first-principles calculations, the cluster expansion formalism, and Monte Carlo simulations. The computed phase diagram of Figure 4 reveals the presence of two main regions characterized by biphasic behavior, which are: i) the $\mathrm{A}+\mathrm{B}$ region that stretches through $\mathrm{Na}$ compositions $0<x<2$ at low temperatures (below $200 \mathrm{~K}$ ) and narrows in composition range with increasing temperature, ii) the miscibility gap, $\mathrm{B}+\mathrm{C}$, in the region $2<x<3$ between 0 and $\sim 650 \mathrm{~K}$. Our result is in stark contrast with experimental literature, which indicates a single phase behavior across the whole region of accessible $\mathrm{Na}$ compositions (i.e., $0 \leq x \leq 3$ ) and temperatures $(>450 \mathrm{~K}$, beyond the region of monoclinic phase stability). ${ }^{9,30,32,33,39,40,72}$ The phase diagram also displays four monophasic regions - A, B, C and C', with $\mathrm{B}$ spanning a noticeably increasing range of $\mathrm{Na}$ concentrations with increasing temperature. Note that $\mathrm{Zr}$ off-stoichiometry is often observed in the rhombohedral- $\mathrm{Na}_{1+\mathrm{x}} \mathrm{Zr}_{2} \mathrm{Si}_{\mathrm{x}} \mathrm{P}_{3-\mathrm{x}} \mathrm{O}_{12}$, with residual $\mathrm{ZrO}_{2}$ found after high-temperature syn- 
thesis and sintering treatments. ${ }^{9,31,39,40,82}$ Our computed phase diagram does not account for $\mathrm{Zr}$ off-stoichiometry, and the inclusion of an additional compositional axis would make this study intractable in terms of computational complexity. However, Boilot et al. ${ }^{32}$ confirmed that $\mathrm{Na}$ migration in vacant $\mathrm{Zr}$ sites is impeded, indicating that $\mathrm{Zr}$ deficiency is less relevant for optimizing the Na-conductivity of this material.

Few experimental reports have targeted the structural characterization of rhombohedral$\mathrm{Na}_{1+\mathrm{x}} \mathrm{Zr}_{2} \mathrm{Si}_{\mathrm{x}} \mathrm{P}_{3-\mathrm{x}} \mathrm{O}_{12}$ at $\mathrm{Na}$ compositions $0<$ $x<2$ or $2<x<3 .{ }^{29,40}$ Notably, most of the early characterization work on rhombohedral $\mathrm{Na}_{1+\mathrm{x}} \mathrm{Zr}_{2} \mathrm{Si}_{\mathrm{x}} \mathrm{P}_{3-\mathrm{x}} \mathrm{O}_{12}$ used single crystal samples with $x \geq 2,{ }^{30,33,72,83,84}$ which were mostly refined according to the structural model of Hong. ${ }^{29}$ While single-crystal X-ray diffraction (XRD) experiments are undoubtedly useful in understanding the structural properties of this material, they may hinder the observation of phase separation in $\mathrm{Na}_{1+\mathrm{x}} \mathrm{Zr}_{2} \mathrm{Si}_{\mathrm{x}} \mathrm{P}_{3-\mathrm{x}} \mathrm{O}_{12}$, in particular, across Na-rich and Na-poor composition domains (e.g., $\mathrm{A}+\mathrm{B}$ and $\mathrm{B}+\mathrm{C}$ in Figure 4), resulting in the lack of identification of unique mono or biphasic domains. For this purpose, advanced powder X-ray or neutron diffraction experiments are required since they should identify phase separation and reveal all the crystalline phases that would eventually coexist in a given sample.

Recent bench ${ }^{31}$ and synchrotron ${ }^{40}$ powder XRD studies demonstrated unequivocally that the low temperature $\mathrm{Na}_{1+\mathrm{x}} \mathrm{Zr}_{2} \mathrm{Si}_{\mathrm{x}} \mathrm{P}_{3-\mathrm{x}} \mathrm{O}_{12}$ compositions behave as a single phase, in contrast to our predictions. For example, Deng et al. ${ }^{40}$ reported a single phase at $\mathrm{Na}_{2} \mathrm{Zr}_{2} \mathrm{Si}_{1} \mathrm{P}_{2} \mathrm{O}_{12}$ at temperatures of 295 and $473 \mathrm{~K}$, which is in the middle of the $\mathrm{A}+\mathrm{B}$ two-phase region (Figure 4). The disagreement in terms of phase stabilities at low temperatures $(<$ $500 \mathrm{~K}$ ) between the theory-predicted thermodynamics (suggesting phase-separation) and experimental reports (indicating single-phase behavior) can be also attributed to kinetic factors. For example, at low temperatures ( $300 \mathrm{~K})$, our predicted phase diagram suggests that $\mathrm{Na}_{3.5} \mathrm{Zr}_{2} \mathrm{Si}_{1} \mathrm{P}_{2} \mathrm{O}_{12}\left(\mathrm{C}^{\prime}\right)$ will phase separate into a mixture of $\mathrm{Na}_{3} \mathrm{Zr}_{2} \mathrm{Si}_{2} \mathrm{P}_{1} \mathrm{O}_{12}(\mathrm{~B})$ and
$\mathrm{Na}_{4} \mathrm{Zr}_{2} \mathrm{Si}_{3} \mathrm{O}_{12}(\mathrm{C})$. This requires the disordered $\mathrm{SiO}_{4}^{4-}$ and $\mathrm{PO}_{4}^{3-}$ ions in the high temperature C' phase to be redistributed in order to form the stable $\mathrm{B}$ and $\mathrm{C}$ phases. The redistribution of the $\mathrm{SiO}_{4}^{4-}$ and $\mathrm{PO}_{4}^{3-}$, which requires macroscopic diffusion of multivalent $\mathrm{Si}^{4+}$ and $\mathrm{P}^{5+}$ ions, would involve high activation barriers that are inaccessible at the lower temperatures to ensure full phase separation. ${ }^{85}$ However, it remains to be verified experimentally (which we will do in the near future) whether prolonged annealing treatments at intermediate temperatures can promote phase separation in $\mathrm{Na}_{1+\mathrm{x}} \mathrm{Zr}_{2} \mathrm{Si}_{\mathrm{x}} \mathrm{P}_{3-\mathrm{x}} \mathrm{O}_{12}$.

Biphasic behavior is typical in NaSiCONbased electrodes. For example, Delmas et al. ${ }^{42}$ detected phase separation of the rhombohedral electrode $\mathrm{Na}_{2} \mathrm{Ti}_{2}\left(\mathrm{PO}_{4}\right)_{3}$ when cooled, leading to the formation of $\mathrm{Na}_{3} \mathrm{Ti}_{2}\left(\mathrm{PO}_{4}\right)_{3}$ and $\mathrm{Na}_{1} \mathrm{Ti}_{2}\left(\mathrm{PO}_{4}\right)_{3}$. For NaSiCON-electrodes with a single transition metal (e.g., $\mathrm{M}=\mathrm{Ti}, \mathrm{V}, \mathrm{Cr}$ and Fe in $\left.\mathrm{Na}_{\mathrm{x}} \mathrm{M}_{2}\left(\mathrm{PO}_{4}\right)_{3}\right)$, the existence of two-phase domains is also observed in electrochemical experiments, whereby the Na-discharge voltage profile exhibits a flat plateau as $\mathrm{Na}$ intercalates in the electrode (see Figure 7). ${ }^{42,47}$ Notably, mechanisms of phase separation in singletransition-metal NaSiCON-electrodes do not involve modifications of the structural framework since phase separation occurs across $\mathrm{Na}$ compositions (i.e., the formation of Na-rich and Na-poor domain) and bond breaking/reforming involving framework atoms (e.g., Ti, V, Cr or $\mathrm{Fe}$ ) is not required, as transition metals do not have to diffuse macroscopically. In other words, the mobile $\mathrm{Na}^{+}$and the accompanying electrons can be redistributed swiftly even at low temperatures $(\sim 300 \mathrm{~K})$ to ensure phase separation. Interestingly, previous studies have claimed that the thermodynamically favorable phase-separation was curbed in mixed transition-metal NaSiCON systems. For example, in $\mathrm{Na}_{2} \mathrm{ZrCr}\left(\mathrm{PO}_{4}\right)_{3}$ the phase separation reaction, 2 $\mathrm{Na}_{2} \mathrm{ZrCr}\left(\mathrm{PO}_{4}\right)_{3} \rightarrow \mathrm{NaZr}_{2}\left(\mathrm{PO}_{4}\right)_{3}+$ $\mathrm{Na}_{3} \mathrm{Cr}_{2}\left(\mathrm{PO}_{4}\right)_{3}$, is inhibited by the slow kinetics of bond-breaking/reforming $\mathrm{Zr}-\mathrm{O}$ and $\mathrm{Cr}-\mathrm{O}$ bonds and the poor macroscopic diffusivity of $\mathrm{Zr}^{4+}$ and $\mathrm{Cr}^{3+} .{ }^{42}$ Notably, phase separation of $\mathrm{Na}_{2} \mathrm{ZrCr}\left(\mathrm{PO}_{4}\right)_{3}$ was not observed 
even after prolonged annealing treatments at high temperatures. Thus, the thermodynamically favored phase separation in rhombohedral$\mathrm{Na}_{1+\mathrm{x}} \mathrm{Zr}_{2} \mathrm{Si}_{\mathrm{x}} \mathrm{P}_{3-\mathrm{x}} \mathrm{O}_{12}$ may also be kinetically inhibited, similar to the mixed transition-metal NaSiCON systems. ${ }^{44}$

To illustrate explicitly the similarity between the phase-separation behavior identified in this work in $\mathrm{Na}_{1+\mathrm{x}} \mathrm{Zr}_{2} \mathrm{Si}_{\mathrm{x}} \mathrm{P}_{3-\mathrm{x}} \mathrm{O}_{12}$ and as observed in NaSiCON electrodes, we schematically superimpose our computed phase diagram (around $295 \mathrm{~K}$ ) onto the experimental voltage charge/discharge curves of the $\mathrm{Na}_{3} \mathrm{Ti}_{2}\left(\mathrm{PO}_{4}\right)_{3}$, $\mathrm{Na}_{3} \mathrm{~V}_{2}\left(\mathrm{PO}_{4}\right)_{3}, \mathrm{Na}_{3} \mathrm{Cr}_{2}\left(\mathrm{PO}_{4}\right)_{3}$ and $\mathrm{Na}_{3} \mathrm{Fe}_{2}\left(\mathrm{PO}_{4}\right)_{3}$ in Figure 7.

Figure 7 shows that as $\mathrm{Na}$ is inserted/extracted into/from $\mathrm{NaM}_{2}\left(\mathrm{PO}_{4}\right)_{3} / \mathrm{Na}_{3} \mathrm{M}_{2}\left(\mathrm{PO}_{4}\right)_{3}(\mathrm{M}=\mathrm{Ti}$, $\mathrm{V}, \mathrm{Cr}$ and $\mathrm{Fe}$ ), the materials always phase separate for $\mathrm{Na}$ concentrations in the range $0<x<2 . \quad \mathrm{Na}_{\mathrm{x}+1} \mathrm{~V}_{2}\left(\mathrm{PO}_{4}\right)_{3}$ also phase separates between $\mathrm{Na}$ concentrations of $2<x<3$. Importantly, Figure 7 identifies that at composition $x=2$ a stable phase (or structure/configuration) is always found and appears to be common to all NaSiCON-based electrodes, analogous to $\mathrm{Na}_{1+\mathrm{x}} \mathrm{Zr}_{2} \mathrm{Si}_{\mathrm{x}} \mathrm{P}_{3-\mathrm{x}} \mathrm{O}_{12}$. Intriguingly, at low temperature and at $x=2$ all of the $\mathrm{Na}(2)$ sites in $\mathrm{Na}_{1+\mathrm{x}} \mathrm{Zr}_{2} \mathrm{Si}_{\mathrm{x}} \mathrm{P}_{3-\mathrm{x}} \mathrm{O}_{12}$ are occupied while the $\mathrm{Na}(1)$ sites have negligible occupations, similar to trends observed in Figure $6 .^{29,33,80}$ On the basis of our entropy curves of Figure 6, we believe that the tendency for $\mathrm{Na}$ to order at composition $x=2$ in $\mathrm{Na}_{3} \mathrm{~V}_{2}\left(\mathrm{PO}_{4}\right)_{3}$, $\mathrm{Na}_{3} \mathrm{Cr}_{2}\left(\mathrm{PO}_{4}\right)_{3}$ and $\mathrm{Na}_{3} \mathrm{Zr}_{2} \mathrm{Si}_{2} \mathrm{P}_{1} \mathrm{O}_{12}$ is significant, and eventually drives the rhombohedral to monoclinic (and their superstructures) phase transition at room temperature. ${ }^{29,73,86}$

In light of these findings one can formulate the following hypothesis:

- Phase separation appears to be the underlying favorable thermodynamic process in $\mathrm{Na}_{1+\mathrm{x}} \mathrm{Zr}_{2} \mathrm{Si}_{\mathrm{x}} \mathrm{P}_{3-\mathrm{x}} \mathrm{O}_{12}$, but is inhibited by the large energy barrier involved in the rearrangement of the $\mathrm{SiO}_{4}^{4-}$ and $\mathrm{PO}_{4}^{3-}$ species.

- Phase separation is fully or partially inhibited, kinetically, whenever cations of the $\mathrm{M}_{2}\left(\mathrm{PO}_{4}\right)_{3}$ framework are required to break bonds, migrate and form new bonds. Analogous to the kinetic impediment to phase separation observed for the solid electrolyte $\mathrm{Na}_{1+\mathrm{x}} \mathrm{Zr}_{2} \mathrm{Si}_{\mathrm{x}} \mathrm{P}_{3-\mathrm{x}} \mathrm{O}_{12}$, partial replacement of $\mathrm{SiO}_{4}^{4-}$ and $\mathrm{PO}_{4}^{3-}$ may also kinetically limit any phase separation in mono-transition metal electrodes. Other "network formers", such as $\mathrm{SiS}_{4}^{4-}$ and $\mathrm{PS}_{4}^{3-}$ found in Li-ion conductors may provide similar effects. ${ }^{87}$

- In both the solid electrolyte and NaSiCON-electrodes, the existence of a stable ordering of Na-ions on the $\mathrm{Na}(2)$ site at the $x=2$ composition is a common feature. The stability of the fully occupied $\mathrm{Na}(2)+$ fully empty $\mathrm{Na}(1)$ configuration might be electrostatically driven (see Section 4.2) and requires further exploration. As is well established in the literature, at low temperatures, this peculiar $\mathrm{Na}$ configuration seems to promote the phase transition from rhombohedral into monoclinic symmetry, with the rhombohedral $\rightarrow$ monoclinic transformation mechanism needing more work to understand fully.

The validation of these hypotheses and their extension to all NaSiCON-derived electrodes requires further experimental and computational investigations.

\subsection{Na Distributions and Ef- fects on $\mathrm{Na}$ Transport in $\mathrm{Na}_{1+\mathrm{x}} \mathrm{Zr}_{2} \mathrm{Si}_{\mathrm{x}} \mathrm{P}_{3-\mathrm{x}} \mathrm{O}_{12}$}

The bulk ionic conductivity of $\mathrm{Na}_{1+\mathrm{x}} \mathrm{Zr}_{2} \mathrm{Si}_{\mathrm{x}} \mathrm{P}_{3-\mathrm{x}} \mathrm{O}_{12}$ is set by the occupations of $\mathrm{Na}(1)$ and $\mathrm{Na}(2)$ sites, ${ }^{31,33,35,37}$ which enables $\mathrm{Na}^{+}$percolation along $\mathrm{Na}(1)-\mathrm{Na}(2)-\mathrm{Na}(1)$ paths. While Zhang et al. ${ }^{37}$ investigated the existence of a $3^{\text {rd }} \mathrm{Na}$ site, $\mathrm{Na}(3)$, located between $\mathrm{Na}(1)$ and $\mathrm{Na}(2)$; $\mathrm{Na}(3)$ is negligibly occupied at high temperatures $200<T<800^{\circ} \mathrm{C}$, hence not relevant to the thermodynamics. Occupancies of $\mathrm{Na}(1)$ and $\mathrm{Na}(2)$ sites are in turn determined by the distribution of $\mathrm{SiO}_{4}^{4-}$ and $\mathrm{PO}_{4}^{3-}$ groups, in order to maintain "local" charge-neutrality within the 


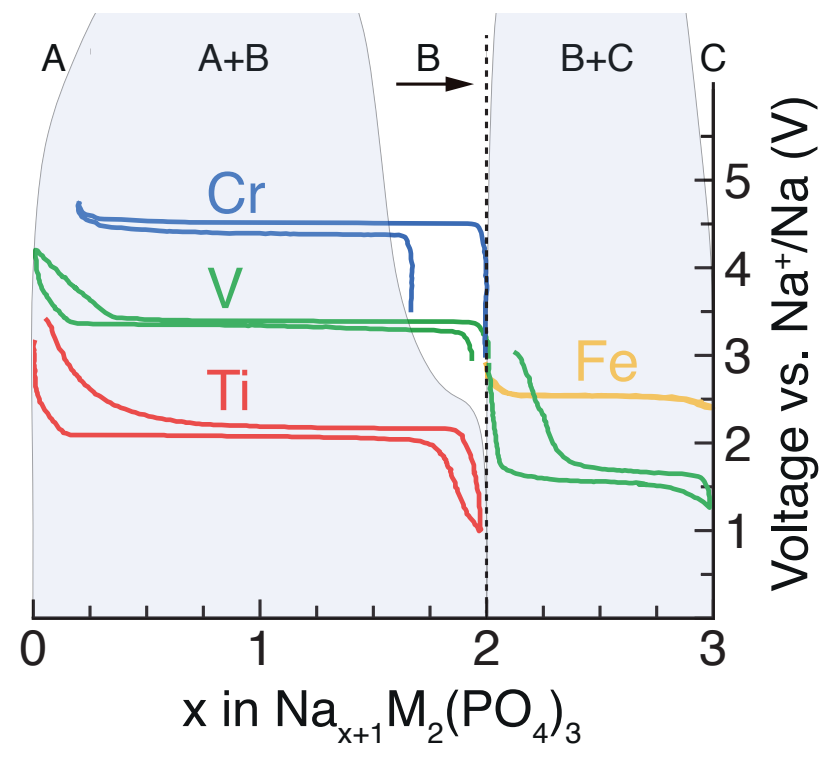

Figure 7: Experimental voltage (vertical axis) charge/discharge curves of $\mathrm{Na}_{3} \mathrm{Ti}_{2}\left(\mathrm{PO}_{4}\right)_{3}$ (in red), $\mathrm{Na}_{3} \mathrm{~V}_{2}\left(\mathrm{PO}_{4}\right)_{3}$ (in green), $\mathrm{Na}_{3} \mathrm{Cr}_{2}\left(\mathrm{PO}_{4}\right)_{3}$ (in blue), and $\mathrm{Na}_{3} \mathrm{Fe}_{2}\left(\mathrm{PO}_{4}\right)_{3}$ (in yellow), adapted from Refs. 43,45,47,81, are superimposed onto the predicted phase diagram of NaSiCON $(\sim 295 \mathrm{~K})$ from Figure 4 . The dashed line and the arrow indicate the ordering at $x=2$.

rhombohedral- $\mathrm{Na}_{1+\mathrm{x}} \mathrm{Zr}_{2} \mathrm{Si}_{\mathrm{x}} \mathrm{P}_{3-\mathrm{x}} \mathrm{O}_{12}$, an aspect that has been rarely discussed in prior experimental reports. Furthermore, the higher mobility of $\mathrm{Na}$ enables $\mathrm{Na}^{+}$ions to adopt energy minimizing configurations, given a $\mathrm{Si} / \mathrm{P}$ arrangement. Thus, the interplay of local charge neutrality, the short and long-range cluster interactions among the $\mathrm{Na}(1)$ and $\mathrm{Na}(2)$ sites, and $\mathrm{Na}^{+}$mobility will control the experimentally observed population of $\mathrm{Na}$ sites at different Na concentrations.

The GCMC data show that the occupation of the $\mathrm{Na}(1)$ site decreases from $x=0$ to $x=2$, and increases monotonically between $x=2$ and $x=3$ below the $\mathrm{B}+\mathrm{C} \rightarrow \mathrm{C}^{\prime}$ transition (see Figure 6). For site $\mathrm{Na}(2)$, we observe a constant increase of its occupation in the range $0<x<2$, while $\mathrm{Na}(2)$ remains fully occupied for $x>2$. The trends in occupancies of $\mathrm{Na}(1)$ and $\mathrm{Na}(2)$ sites are in excellent agreement with the experimental study of Boilot et al. ${ }^{33}$ Importantly, the highest Na-conductivity observed in the rhombohedral structure is at $x \sim 2$, which coincides with the high degree of occupation of $\mathrm{Na}(2)$ sites and the largely empty $\mathrm{Na}(1)$ sites. The selective occupation of $\mathrm{Na}(2)$ sites at $x \sim 2$ can be attributed to the shorter distance between
$\mathrm{Na}(2)$ sites and $\mathrm{XO}_{4}$ tetrahedra, where the increasing occupation of $\mathrm{Si}$ in the $\mathrm{XO}_{4}$ units with increasing $\mathrm{x}$ can electrostatically favor $\mathrm{Na}$ occupation of $\mathrm{Na}(2)$ sites. However, it remains to be seen how specific configurations of $\mathrm{Na} / \mathrm{Va}$ and $\mathrm{Si} / \mathrm{P}$ affect the microscopic migration barriers that govern the overall Na-transport. Hence, it is important to extend our model by incorporating migration barriers, as a function of $\mathrm{Na}$ content and temperature, which will be the focus of future work.

\section{Conclusion}

In this work, we investigated the phase stability of the high-temperature $\mathrm{Na}_{1+\mathrm{x}} \mathrm{Zr}_{2} \mathrm{Si}_{\mathrm{x}} \mathrm{P}_{3-\mathrm{x}} \mathrm{O}_{12}$ ionic conductor using a multi-scale approach based on first-principles calculations, a cluster expansion framework, and large-size Monte Carlo simulations. We observed excellent agreement with DFT predicted structural properties, namely lattice volumes, c and a parameters, with measurements. Additionally, we found that the selective occupation of $\mathrm{Na}(2)$ sites instead of $\mathrm{Na}(1)$ sites drives the stability of the $\mathrm{Na}_{3} \mathrm{Zr}_{2} \mathrm{Si}_{2} \mathrm{P}_{1} \mathrm{O}_{12}$ ground state, particularly 
at low temperatures. The computed phase diagram suggests that $\mathrm{Na}_{1+\mathrm{x}} \mathrm{Zr}_{2} \mathrm{Si}_{\mathrm{x}} \mathrm{P}_{3-\mathrm{x}} \mathrm{O}_{12}$ would phase separate into three distinct single-phase domains at low temperature, in contrast with experimental observations so far. Kinetic limitations, specifically the macroscopic diffusion of $\mathrm{Si}^{4+}$ and $\mathrm{P}^{5+}$ ions, may inhibit the phase separation into $\mathrm{Na}+\mathrm{Si}$-rich and $\mathrm{Va}+\mathrm{P}$-rich domains in experiments. We identified similarities in phase behavior between the NaSiCONelectrolyte and mono-transition-metal NaSiCON electrodes, which typically phase separate upon $\mathrm{Na}$ extraction/insertion. Interestingly, the lack of phase separation observed in mixedtransition-metal NaSiCON electrodes may be attributed to kinetic limitations, similar to the scenario in $\mathrm{Na}_{1+\mathrm{x}} \mathrm{Zr}_{2} \mathrm{Si}_{\mathrm{x}} \mathrm{P}_{3-\mathrm{x}} \mathrm{O}_{12}$. Therefore, we speculate that the introduction of $\mathrm{SiO}_{4}^{4-}$ into phosphate-based electrodes can inhibit kinetically phenomena of phase separation. Based on our phase diagram, we also unveil the complex interplay by $\mathrm{Na}$ sites occupation at different temperatures and electrostatic. With this understanding, we could identify and explain why experimentally only specific compositions offers high Na-transport. Finally, our work offers important insights on the role of $\mathrm{Na}-\mathrm{Va}$ and Si-P configurations on the stability and Natransport properties of NaSiCON-electrolytes and will be an important addition in the development of safe and sustainable Na-ion batteries.

\section{Author Contribution}

P.C. designed supervised every aspect of the project. Z. D. and P. C. performed the DFT calculations and fitted the cluster expansion model. Z. D. Modified the CASM code, performed the Monte Carlo calculations and carried out the data analysis. Z. D. and P. C. wrote the first draft. Z. D., P. C., G. S. G. and A. K. C. contributed to the initial data analysis of the computed data. All the authors contributed to the discussion and the final version of this manuscript.

Acknowledgement P. C., C. M., A. K. C. and J.-N. C. are grateful to the ANR-NRF
NRF2019-NRF-ANR073 Na-MASTER. P. C. acknowledges funding from the National Research Foundation under his NRF Fellowship NRFF12-2020-0012. A. K. C., J. D. and P. C. are grateful to the Green Energy programme under the project code R284-000-185731. The computational work was performed on resources of the National Supercomputing Centre, Singapore (https://www.nscc.sg). P. C. is thankful to Prof. Anton Van der Ven and Prof. Ram Seshadri for hosting Z. D. in their groups at U.C. Santa Barbara.

\section{Supporting Information Avail- able}

The Supporting Information contains: i) the detail of the $\mathrm{CE}$ model, ii) a detailed description of the Monte Carlo simulation, iii) the identification of the phase boundaries, and iv) a discussion on the free-energy integration. All the computational data associated with this study are freely available at the repository https://github.com/caneparesearch/ NaZrSiPO-paper-data.

\section{References}

(1) Tarascon, J.-M. Nat. Chem. 2010, 2, 510510.

(2) Kim, S.-W.; Seo, D.-H.; Ma, X.; Ceder, G.; Kang, K. Adv. Energy Mater. 2012, 2, 710-721.

(3) Clément, R. J.; Bruce, P. G.; Grey, C. P. J. Electrochem. Soc. 2015, 162, A2589 A2604.

(4) Goodenough, J. B.; Kim, Y. Chem. Mater. 2010, 22, 587-603.

(5) Bachman, J. C.; Muy, S.; Grimaud, A.; Chang, H.-H.; Pour, N.; Lux, S. F.; Paschos, O.; Maglia, F.; Lupart, S.; Lamp, P.; Giordano, L.; Shao-Horn, Y. Chem. Rev. 2015, 116, 140-162. 
(6) Janek, J.; Zeier, W. G. Nat Energy 2016, 1,16141 .

(7) Mizuno, F.; Hayashi, A.; Tadanaga, K.; Tatsumisago, M. Adv. Mater. 2005, 17, 918-921.

(8) Kuhn, A.; Duppel, V.; Lotsch, B. V. Energy Environ. Sci. 2013, 6, 3548.

(9) Lalère, F.; Leriche, J.; Courty, M.; Boulineau, S.; Viallet, V.; Masquelier, C.; Seznec, V. J. Power Sources 2014, 247, 975-980.

(10) Zhu, Y.; He, X.; Mo, Y. ACS Appl. Mater. Interfaces 2015, 7, 23685-23693.

(11) Zhou, W.; Li, Y.; Xin, S.; Goodenough, J. B. ACS Cent. Sci. 2017, 3, 5257.

(12) Yu, C.; Ganapathy, S.; Eck, E. R. H. v.; Wang, H.; Basak, S.; Li, Z.; Wagemaker, M. Nat. Commun. 2017, 8, 1086.

(13) El-Shinawi, H.; Regoutz, A.; Payne, D. J.; Cussen, E. J.; Corr, S. A. J. Mater. Chem. A 2018, 6, 5296-5303.

(14) Zhang, Z.; Shao, Y.; Lotsch, B.; Hu, Y.-S.; Li, H.; Janek, J.; Nazar, L. F.; Nan, C.W.; Maier, J.; Armand, M.; Chen, L. Energy Environ. Sci. 2018, 11, 1945-1976.

(15) Dawson, J. A.; Canepa, P.; Famprikis, T.; Masquelier, C.; Islam, M. S. J. Am. Chem. Soc. 2018, 140, 362-368.

(16) Kahle, L.; Marcolongo, A.; Marzari, N. Phys. Rev. Materials 2018, 2, 065405.

(17) Famprikis, T.; Canepa, P.; Dawson, J. A.; Islam, M. S.; Masquelier, C. Nat. Mater. 2019,

(18) Nolan, A. M.; Liu, Y.; Mo, Y. ACS Energy Lett. 2019, 4, 2444-2451.

(19) Uchida, Y.; Hasegawa, G.; Shima, K.; Inada, M.; Enomoto, N.; Akamatsu, H.; Hayashi, K. ACS Appl. Energy Mater. 2019, 2, 2913-2920.
(20) Schlem, R.; Till, P.; Weiss, M.; Krauskopf, T.; Culver, S. P.; Zeier, W. G. Chem. Eur. J. 2019, 25, 4143-4148.

(21) Hayashi, A.; Masuzawa, N.; Yubuchi, S.; Tsuji, F.; Hotehama, C.; Sakuda, A.; Tatsumisago, M. Nat. Commun. 2019, 10, 5266 .

(22) Schwietert, T. K.; Arszelewska, V. A.; Wang, C.; Yu, C.; Vasileiadis, A.; de Klerk, N. J. J.; Hageman, J.; Hupfer, T.; Kerkamm, I.; Xu, Y.; van der Maas, E.; Kelder, E. M.; Ganapathy, S.; Wagemaker, M. Nat. Mater. 2020, 19, 428-435.

(23) Kahle, L.; Marcolongo, A.; Marzari, N. Energy Environ. Sci. 2020, 13, 928-948.

(24) Binninger, T.; Marcolongo, A.; Mottet, M.; Weber, V.; Laino, T. J. Mater. Chem. A 2020, 8, 1347-1359.

(25) Kamaya, N.; Homma, K.; Yamakawa, Y.; Hirayama, M.; Kanno, R.; Yonemura, M.; Kamiyama, T.; Kato, Y.; Hama, S.; Kawamoto, K.; Mitsui, A. Nat. Mater. 2011, 10, 682-686.

(26) Kato, Y.; Hori, S.; Saito, T.; Suzuki, K.; Hirayama, M.; Mitsui, A.; Yonemura, M.; Iba, H.; Kanno, R. Nature Energy 2016, 1,16030 .

(27) Gao, Y.; Nolan, A. M.; Du, P.; Wu, Y.; Yang, C.; Chen, Q.; Mo, Y.; Bo, S.-H. Chem. Rev. 2020, Publisher: American Chemical Society.

(28) Wang, Y.; Richards, W. D.; Ong, S. P.; Miara, L. J.; Kim, J. C.; Mo, Y.; Ceder, G. Nature Mater 2015, 14, 1026-1031.

(29) Hong, H.-P. Mater. Res. Bull. 1976, 11, $173-182$.

(30) Goodenough, J.; Hong, H.-P.; Kafalas, J. Mater. Res. Bull. 1976, 11, 203-220.

(31) Ma, Q.; Tsai, C.-L.; Wei, X.-K.; Heggen, M.; Tietz, F.; Irvine, J. T. S. J. Mater. Chem. A 2019, 7, 7766-7776. 
(32) Boilot, J.; Collin, G.; Colomban, P. Mater. Res. Bull. 1987, 22, 669-676.

(33) Boilot, J.; Collin, G.; Colomban, P. J. Solid State Chem. 1988, 73, 160-171.

(34) Delmas, C.; Viala, J.; Olazcuaga, R.; Leflem, G.; Hagenmuller, P.; Cherkaoui, F.; Brochu, R. Solid State Ionics 1981, 3-4, 209-214.

(35) Kohler, H.; Schulz, H. Mater. Res. Bull. 1985, 20, 1461-1471.

(36) Losilla, E. R.; Aranda, M. A. G.; Bruque, S.; París, M. A.; Sanz, J.; West, A. R. Chem. Mater. 1998, 10, 665673.

(37) Zhang, Z.; Zou, Z.; Kaup, K.; Xiao, R.; Shi, S.; Avdeev, M.; Hu, Y.-S.; Wang, D.; He, B.; Li, H.; Huang, X.; Nazar, L. F.; Chen, L. Adv. Energy Mater. 2019, 9, 1902373.

(38) Jolley, A. G.; Cohn, G.; Hitz, G. T.; Wachsman, E. D. Ionics 2015, 21, 30313038 .

(39) Ma, Q.; Guin, M.; Naqash, S.; Tsai, C.-L.; Tietz, F.; Guillon, O. Chem. Mater. 2016, 28, 4821-4828.

(40) Deng, Y.; Eames, C.; Nguyen, L. H. B.; Pecher, O.; Griffith, K. J.; Courty, M.; Fleutot, B.; Chotard, J.-N.; Grey, C. P.; Islam, M. S.; Masquelier, C. Chem. Mater. 2018, 30, 2618-2630.

(41) Miyajima, Y.; Miyoshi, T.; Tamaki, J.; Matsuoka, M.; Yamamoto, Y.; Masquelier, C.; Tabuchi, M.; Saito, Y.; Kageyama, H. Solid State Ionics 1999, 11 .

(42) Delmas, C.; Nadiri, A.; Soubeyroux, J. L. Solid State Ionics 1988, 28-30, 419-423.

(43) Patoux, S.; Rousse, G.; Leriche, J.-B.; Masquelier, C. Chem. Mater. 2003, 15, 2084-2093.
(44) Masquelier, C.; Croguennec, L. Chem. Rev. 2013, 113, 6552-6591.

(45) Senguttuvan, P.; Rousse, G.; Arroyo y de Dompablo, M. E.; Vezin, H.; Tarascon, J.M.; Palacín, M. R. J. Am. Chem. Soc. 2013, 135, 3897-3903.

(46) Chen, F.; Kovrugin, V. M.; David, R.; Mentré, O.; Fauth, F.; Chotard, J.; Masquelier, C. Small Methods 2019, 3, 1800218.

(47) Kawai, K.; Zhao, W.; Nishimura, S.-i.; Yamada, A. ACS Appl. Energy Mater. 2018, 1, 928-931.

(48) Sanchez, J.; Ducastelle, F.; Gratias, D. Physica A 1984, 128, 334-350.

(49) Hohenberg, P.; Kohn, W. Phys. Rev. 1964, 136, B864-B871.

(50) Kohn, W.; Sham, L. J. Phys. Rev. 1965, 140, A1133-A1138.

(51) Binder, K.; Heermann, D. W. In Monte Carlo Simulation in Statistical Physics: An Introduction; Binder, K., Heermann, D. W., Eds.; Graduate Texts in Physics; Springer: Berlin, Heidelberg, 2010; pp 5-67.

(52) Van der Ven, A.; Thomas, J.; Xu, Q.; Bhattacharya, J. Math. Comput. Simul 2010, 80, 1393-1410.

(53) Puchala, B.; Van der Ven, A. Phys. Rev. B 2013, 88, 094108.

(54) Thomas, J. C.; Ven, A. V. d. Phys. Rev. $B$ 2013, 88, 214111.

(55) Developers, C. Casmcode: V0.2.1. 2017; https://zenodo.org/record/546148.

(56) Van der Ven, A.; Deng, Z.; Banerjee, S.; Ong, S. P. Chem. Rev. 2020, acs.chemrev.9b00601.

(57) Zhou, F.; Maxisch, T.; Ceder, G. Phys. Rev. Lett. 2006, 97, 155704. 
(58) Nelson, L. J.; Hart, G. L. W.; Zhou, F.; Ozoliňš, V. Phys. Rev. B 2013, 87, 035125 .

(59) Ong, S. P.; Richards, W. D.; Jain, A.; Hautier, G.; Kocher, M.; Cholia, S.; Gunter, D.; Chevrier, V. L.; Persson, K. A.; Ceder, G. Computational Materials Science 2013, 68, 314-319.

(60) Qui, D.; Capponi, J.; Joubert, J.; Shannon, R. J. Solid State Chem. 1981, 39, 219-229.

(61) Ewald, P. P. Ann. Phys. 1921, 369, 253287.

(62) Kresse, G.; Furthmüller, J. Phys. Rev. B 1996, 54, 11169-11186.

(63) Kresse, G.; Furthmüller, J. Computational Materials Science 1996, 6, 15-50, 32372.

(64) Sun, J.; Ruzsinszky, A.; Perdew, J. Phys. Rev. Lett. 2015, 115, 036402.

(65) Sai Gautam, G.; Carter, E. A. Phys. Rev. Materials 2018, 2, 095401.

(66) Bartel, C. J.; Weimer, A. W.; Lany, S.; Musgrave, C. B.; Holder, A. M. npj Comput. Mater. 2019, 5, 4.

(67) Wang, J.; Wang, Y.; Seo, D.; Shi, T.; Chen, S.; Tian, Y.; Kim, H.; Ceder, G. Adv. Energy Mater. 2020, 10, 1903968.

(68) Blöchl, P. E. Phys. Rev. B 2000, 62, 6158-6179.

(69) Kresse, G.; Joubert, D. Phys. Rev. B 1999, 59, 1758-1775.

(70) Monkhorst, H. J.; Pack, J. D. Phys. Rev. B 1976, 13, 5188-5192.

(71) Qui, D.; Capponi, J.; Gondrand, M.; Saib, M.; Joubert, J.; Shannon, R. Solid State Ionics 1981, 3-4, 219-222.

(72) Boilot, J. P.; Salani, J. P. Mater. Res. Bull. 1979, 14, 9.
(73) Chotard, J.-N.; Rousse, G.; David, R.; Mentré, O.; Courty, M.; Masquelier, C. Chem. Mater. 2015, 27, 5982-5987.

(74) van de Walle, A.; Asta, M. Modell. Simul. Mater. Sci. Eng. 2002, 10, 19.

(75) Hazen, R. M.; Finger, L. W.; Agrawal, D. K.; McKinstry, H. A.; Perrotta, A. J. J. Mater. Res. 1987, 2, 329-337, Publisher: Cambridge University Press.

(76) Didisheim, J.; Prince, E.; Wuensch, B. Solid State Ionics 1986, 18-19, 944-958.

(77) Kohler, H.; Schulz, H.; Melnikov, O. Mater. Res. Bull. 1983, 18, 589-592.

(78) Hagman, L.-O.; Kierkegaard, P.; Karvonen, P.; Virtanen, A. I.; Paasivirta, J. Acta Chem. Scand. 1968, 22, 1822-1832.

(79) Kamali, K.; Ravindran, T.; Chandra Shekar, N.; Pandey, K.; Sharma, S. J. Solid State Chem. 2015, 221, 285-290.

(80) Baur, W. H.; Dygas, J. R.; Whitmore, D. H.; Faber, J. Solid State Ionics 1986, 18-19, 9.

(81) Patoux, S. Propriétés structurales et électrochimiques de phosphates d'éléments de transition. Ph.D. thesis, Université de Picardie Jules Verne, Amiens, 2003.

(82) Gordon, R.; Miller, G.; Mcentire, B.; Beck, E.; Rasmussen, J. Solid State Ionics 1981, 3-4, 243-248.

(83) Kohler, H.; Schulz, H.; Melnikov, O. Mater. Res. Bull. 1983, 18, 1143-1152.

(84) Kohler, H.; Schulz, H. Mater. Res. Bull. 1986, 21, 23-31.

(85) Lalère, F.; Seznec, V.; Courty, M.; David, R.; Chotard, J. N.; Masquelier, C. J. Mater. Chem. A 2015, 3, 16198-16205.

(86) d'Yvoire, F.; Pintard-Scrépel, M.; Bretey, E.; de la Rochère, M. Solid State Ionics 1983, 9-10, 851-857. 
(87) Kanno, R.; Murayama, M. J. Electrochem.

Soc. 2001, 148, 5 . 


\section{Phase Behavior in NaSiCON}

\section{Electrolytes and Electrodes}

\section{-Supplementary Information-}

Zeyu Deng, ${ }^{\dagger}$ Gopalakrishnan Sai Gautam, ${ }^{\ddagger}$ Sanjeev Krishna Kolli, $₫$ Jean-Noël

Chotard, ${ }^{\S}, \|$ Anthony K. Cheetham, ${ }^{\dagger,}$ Christian Masquelier,,,$\|$ and Pieremanuele Canepa*,

$\dagger$ Department of Materials Science and Engineering, National University of Singapore, 9 Engineering Drive 1, Singapore

$\ddagger$ Department of Mechanical and Aerospace Engineering, Princeton University, Princeton, New Jersey 08544, United States

IMaterials Department and Materials Research Laboratory, University of California, Santa Barbara, California 93106, United States

$\S$ Laboratoire de Réactivité et Chimie des Solides, UMR CNRS \#7314, Université de Picardie Jules Verne, 80039 Amiens Cedex, France

||RS2E, Réseau Français sur le Stockage Electrochimique de l'Energie, FR CNRS \#3459, F-80039 Amiens Cedex 1, France

E-mail: pcanepa@nus.edu.sg 


\section{Contents}

S1 Model Structure of $\mathrm{Na}_{1+\mathrm{x}} \mathrm{Zr}_{2} \mathrm{Si}_{\mathrm{x}} \mathrm{P}_{3-\mathrm{x}} \mathrm{O}_{12}$

S2 Analysis of the Effective Cluster Interactions $\quad 4$

S3 Basis of the Cluster Expansion and ECI assignation 9

$\begin{array}{ll}\text { S4 Thermodynamic Integration } & 10\end{array}$

S5 Example of Monte Carlo Snapshot $\quad 13$

$\begin{array}{ll}\text { References } & 14\end{array}$ 


\section{S1 Model Structure of $\mathrm{Na}_{1+\mathrm{x}} \mathrm{Zr}_{2} \mathrm{Si}_{\mathrm{x}} \mathrm{P}_{3-\mathrm{x}} \mathrm{O}_{12}$}

Table $\mathrm{S} 1$ shows the atom labels and coordinates of the model-structure cell of $\mathrm{Na}_{1+\mathrm{x}} \mathrm{Zr}_{2} \mathrm{Si}_{\mathrm{x}} \mathrm{P}_{3-\mathrm{x}} \mathrm{O}_{12}$ on which the cluster expansion is fitted.

Table S1: Atom labels and fractional coordinates of the model-structure cell of $\mathrm{Na}_{1+\mathrm{x}} \mathrm{Zr}_{2} \mathrm{Si}_{\mathrm{x}} \mathrm{P}_{3-\mathrm{x}} \mathrm{O}_{12}$ in the rhombohedral representation. Space group $R \overline{3} c$ No. 167, lattice constants $a=9.099 \AA$ and $\alpha=60.634^{\circ}$ as obtained from Ref. 1, ICSD \# 15546, with stoichiometry $\mathrm{Na}_{4} \mathrm{Zr}_{2} \mathrm{Si}_{3} \mathrm{O}_{12}$. The types of $\mathrm{Na}$, i.e. $\mathrm{Na}(1)$ and $\mathrm{Na}(2)$ in reference to Figure 1 in the main article are also indicated.

\begin{tabular}{ccccc}
\hline Atomic species & Label site & $\mathbf{x}$ & $\mathbf{y}$ & $\mathbf{z}$ \\
\hline $\mathrm{Na} / \mathrm{Va}$ & $0 \mathrm{Na}(1)$ & 0.500000 & 0.500000 & 0.500000 \\
$\mathrm{Na} / \mathrm{Va}$ & $1 \mathrm{Na}(1)$ & 0.000000 & 0.000000 & 0.000000 \\
$\mathrm{Na} / \mathrm{Va}$ & $2 \mathrm{Na}(2)$ & 0.889670 & 0.610330 & 0.250000 \\
$\mathrm{Na} / \mathrm{Va}$ & $3 \mathrm{Na}(2)$ & 0.610330 & 0.250000 & 0.889670 \\
$\mathrm{Na} / \mathrm{Va}$ & $4 \mathrm{Na}(2)$ & 0.250000 & 0.889670 & 0.610330 \\
$\mathrm{Na} / \mathrm{Va}$ & $5 \mathrm{Na}(2)$ & 0.389670 & 0.750000 & 0.110330 \\
$\mathrm{Na} / \mathrm{Va}$ & $6 \mathrm{Na}(2)$ & 0.750000 & 0.110330 & 0.389670 \\
$\mathrm{Na} / \mathrm{Va}$ & $7 \mathrm{Na}(2)$ & 0.110330 & 0.389670 & 0.750000 \\
\hline $\mathrm{Zr}$ & 8 & 0.352810 & 0.352810 & 0.352810 \\
$\mathrm{Zr}$ & 9 & 0.852810 & 0.852810 & 0.852810 \\
$\mathrm{Zr}$ & 10 & 0.647190 & 0.647190 & 0.647190 \\
$\mathrm{Zr}$ & 11 & 0.147190 & 0.147190 & 0.147190 \\
$\mathrm{Si} / \mathrm{P}$ & 12 & 0.545440 & 0.954560 & 0.250000 \\
$\mathrm{Si} / \mathrm{P}$ & 13 & 0.954560 & 0.250000 & 0.545440 \\
$\mathrm{Si} / \mathrm{P}$ & 14 & 0.250000 & 0.545440 & 0.954560 \\
$\mathrm{Si} / \mathrm{P}$ & 15 & 0.045440 & 0.750000 & 0.454560 \\
$\mathrm{Si} / \mathrm{P}$ & 16 & 0.750000 & 0.454560 & 0.045440 \\
$\mathrm{Si} / \mathrm{P}$ & 17 & 0.454560 & 0.045440 & 0.750000 \\
\hline $\mathrm{O}$ & 18 & 0.432310 & 0.228140 & 0.579990 \\
$\mathrm{O}$ & 19 & 0.228140 & 0.579990 & 0.432310 \\
$\mathrm{O}$ & 20 & 0.579990 & 0.432310 & 0.228140 \\
$\mathrm{O}$ & 21 & 0.932310 & 0.079990 & 0.728140 \\
$\mathrm{O}$ & 22 & 0.079990 & 0.728140 & 0.932310 \\
$\mathrm{O}$ & 23 & 0.728140 & 0.932310 & 0.079990 \\
$\mathrm{O}$ & 24 & 0.567690 & 0.771860 & 0.420010 \\
$\mathrm{O}$ & 25 & 0.771860 & 0.420010 & 0.567690 \\
$\mathrm{O}$ & 26 & 0.420010 & 0.567690 & 0.771860 \\
$\mathrm{O}$ & 27 & 0.067690 & 0.920010 & 0.271860 \\
$\mathrm{O}$ & 28 & 0.920010 & 0.271860 & 0.067690 \\
$\mathrm{O}$ & 29 & 0.271860 & 0.067690 & 0.920010 \\
$\mathrm{O}$ & 30 & 0.469130 & 0.125870 & 0.329030 \\
$\mathrm{O}$ & 31 & 0.125870 & 0.329030 & 0.469130 \\
$\mathrm{O}$ & 32 & 0.329030 & 0.469130 & 0.125870 \\
$\mathrm{O}$ & 33 & 0.969130 & 0.829030 & 0.625870 \\
$\mathrm{O}$ & 34 & 0.829030 & 0.625870 & 0.969130 \\
$\mathrm{O}$ & 35 & 0.625870 & 0.969130 & 0.829030 \\
$\mathrm{O}$ & 36 & 0.530870 & 0.874130 & 0.670970 \\
$\mathrm{O}$ & 37 & 0.874130 & 0.670970 & 0.530870 \\
$\mathrm{O}$ & 0.670970 & 0.530870 & 0.874130 \\
$\mathrm{O}$ & 0.030870 & 0.170970 & 0.374130 \\
$\mathrm{O}$ & 0.170970 & 0.374130 & 0.030870 \\
$\mathrm{O}$ & 0.374130 & 0.030870 & 0.170970 \\
\hline & & & & \\
\hline & 38 & & & \\
\hline & & & & \\
$\mathrm{O}$ & & & &
\end{tabular}




\section{S2 Analysis of the Effective Cluster Interactions}

Table S2 and Figure S1 report the characteristics of the 65 distinct effective cluster interactions (ECIs) of the $\mathrm{Na}_{1+\mathrm{x}} \mathrm{Zr}_{2} \mathrm{Si}_{\mathrm{x}} \mathrm{P}_{3-\mathrm{x}} \mathrm{O}_{12}$ system in our cluster expansion (CE) model. Figure S1 plots the most significant ECIs (normalised by their multiplicity) as function of their index \#.

Table S2: ECIs. Point term $\mathcal{P} \mathcal{T}$, pair $\mathcal{P}$, triplet $\mathcal{T}$, and quadruplet $\mathcal{Q}$ terms. Site refer to the label sites given in Table S1. Cell $[0,0,0]$ is the reference cell. $\mathrm{M}$ is the multiplicity of each cluster.

\begin{tabular}{|c|c|c|c|c|c|c|c|c|}
\hline Index & Cluster Index & Type & Site(Label) & Cell & Min. (Å) & Max. $(\AA)$ & ECI (meV) & $\mathrm{ECI} / \mathrm{M}(\mathrm{meV})$ \\
\hline 1 & 4 & $\mathcal{P} \mathcal{T}$ & $\mathrm{Na} / \mathrm{Va}(3)$ & {$[0,0,0]$} & - & - & +54.194 & +27.097 \\
\hline 2 & 5 & $\mathcal{P}$ & $\begin{array}{l}\mathrm{Na} / \mathrm{Va}(3) \\
\mathrm{Si} / \mathrm{P}(14)\end{array}$ & $\begin{array}{l}{[0,0,0]} \\
{[0,0,0]}\end{array}$ & 3.055 & 3.055 & -399.759 & -33.313 \\
\hline 3 & 6 & $\mathcal{P}$ & $\begin{array}{l}\mathrm{Na} / \mathrm{Va}(0) \\
\mathrm{Na} / \mathrm{Va}(3)\end{array}$ & $\begin{array}{l}{[0,0,0]} \\
{[0,0,0]}\end{array}$ & 3.162 & 3.162 & -435.435 & -72.572 \\
\hline 4 & 8 & $\mathcal{P}$ & $\begin{array}{l}\mathrm{Na} / \mathrm{Va}(3) \\
\mathrm{Si} / \mathrm{P}(17)\end{array}$ & $\begin{array}{l}{[0,0,0]} \\
{[0,0,0]}\end{array}$ & 3.710 & 3.710 & -570.255 & -47.521 \\
\hline 5 & 12 & $\mathcal{P}$ & $\begin{array}{l}\mathrm{Na} / \mathrm{Va}(3) \\
\mathrm{Na} / \mathrm{Va}(6)\end{array}$ & $\begin{array}{l}{[0,0,0]} \\
{[0,0,0]}\end{array}$ & 4.727 & 4.727 & -42.419 & -3.535 \\
\hline 6 & 13 & $\mathcal{P}$ & $\begin{array}{l}\mathrm{Si} / \mathrm{P}(14) \\
\mathrm{Si} / \mathrm{P}(15)\end{array}$ & $\begin{array}{c}{[0,0,0]} \\
{[0,-1,1]}\end{array}$ & 4.922 & 4.922 & +141.637 & +11.803 \\
\hline 7 & 14 & $\mathcal{P}$ & $\begin{array}{l}\mathrm{Na} / \mathrm{Va}(3) \\
\mathrm{Na} / \mathrm{Va}(5)\end{array}$ & $\begin{array}{c}{[0,0,0]} \\
{[0,1,-1]}\end{array}$ & 4.980 & 4.980 & +58.296 & +9.716 \\
\hline 8 & 15 & $\mathcal{P}$ & $\begin{array}{l}\mathrm{Na} / \mathrm{Va}(3) \\
\mathrm{Na} / \mathrm{Va}(4)\end{array}$ & $\begin{array}{c}{[0,0,0]} \\
{[1,-1,0]}\end{array}$ & 5.102 & 5.102 & +1193.520 & +99.460 \\
\hline 9 & 19 & $\mathcal{P}$ & $\begin{array}{l}\mathrm{Na} / \mathrm{Va}(3) \\
\mathrm{Si} / \mathrm{P}(15)\end{array}$ & $\begin{array}{c}{[0,0,1]} \\
{[1,-1,0]}\end{array}$ & 6.056 & 6.056 & -385.829 & -32.152 \\
\hline 10 & 20 & $\mathcal{P}$ & $\begin{array}{l}\mathrm{Si} / \mathrm{P}(14) \\
\mathrm{Na} / \mathrm{Va}(0)\end{array}$ & $\begin{array}{l}{[0,0,0]} \\
{[0,0,1]}\end{array}$ & 6.173 & 6.173 & +46.582 & +3.882 \\
\hline 11 & 21 & $\mathcal{P}$ & $\begin{array}{l}\mathrm{Na} / \mathrm{Va}(3) \\
\mathrm{Si} / \mathrm{P}(14)\end{array}$ & $\begin{array}{c}{[0,0,0]} \\
{[1,-1,0]}\end{array}$ & 6.196 & 6.196 & -17.857 & -1.488 \\
\hline 12 & 22 & $\mathcal{P}$ & $\begin{array}{l}\mathrm{Na} / \mathrm{Va}(3) \\
\mathrm{Si} / \mathrm{P}(17)\end{array}$ & $\begin{array}{l}{[0,0,0]} \\
{[0,1,0]}\end{array}$ & 6.220 & 6.220 & -352.738 & -29.395 \\
\hline 13 & 24 & $\mathcal{P}$ & $\begin{array}{l}\mathrm{Na} / \mathrm{Va}(3) \\
\mathrm{Na} / \mathrm{Va}(0)\end{array}$ & $\begin{array}{l}{[0,0,0]} \\
{[0,0,1]}\end{array}$ & 6.465 & 6.465 & +468.440 & +39.037 \\
\hline 14 & 27 & $\mathcal{P}$ & $\begin{array}{l}\mathrm{Na} / \mathrm{Va}(3) \\
\mathrm{Na} / \mathrm{Va}(0)\end{array}$ & $\begin{array}{c}{[0,0,0]} \\
{[0,-1,1]}\end{array}$ & 6.519 & 6.519 & +913.329 & +76.111 \\
\hline 15 & 30 & $\mathcal{P}$ & $\begin{array}{l}\mathrm{Na} / \mathrm{Va}(3) \\
\mathrm{Si} / \mathrm{P}(15)\end{array}$ & $\begin{array}{c}{[0,0,0]} \\
{[0,-1,1]}\end{array}$ & 6.901 & 6.901 & +339.229 & +28.269 \\
\hline 16 & 31 & $\mathcal{P}$ & $\mathrm{Na} / \mathrm{Va}(3)$ & {$[0,0,0]$} & 6.956 & 6.956 & +11.663 & +1.944 \\
\hline
\end{tabular}




\begin{tabular}{|c|c|c|c|c|c|c|c|c|}
\hline & & & $\mathrm{Na} / \mathrm{Va}(5)$ & {$[0,0,0]$} & & & & \\
\hline 17 & 32 & $\mathcal{P}$ & $\begin{array}{l}\mathrm{Si} / \mathrm{P}(14) \\
\mathrm{Si} / \mathrm{P}(15)\end{array}$ & $\begin{array}{l}{[0,0,0]} \\
{[1,0,0]}\end{array}$ & 7.012 & 7.012 & +3.121 & +0.260 \\
\hline 18 & 33 & $\mathcal{P}$ & $\begin{array}{l}\mathrm{Na} / \mathrm{Va}(3) \\
\mathrm{Na} / \mathrm{Va}(7)\end{array}$ & $\begin{array}{c}{[0,0,0]} \\
{[1,-1,0]}\end{array}$ & 7.263 & 7.263 & -61.571 & -5.131 \\
\hline 19 & 34 & $\mathcal{P}$ & $\begin{array}{l}\mathrm{Na} / \mathrm{Va}(3) \\
\mathrm{Na} / \mathrm{Va}(4)\end{array}$ & $\begin{array}{c}{[0,0,0]} \\
{[0,-1,0]}\end{array}$ & 7.406 & 7.406 & +670.671 & +111.779 \\
\hline 20 & 36 & $\mathcal{P}$ & $\begin{array}{l}\mathrm{Si} / \mathrm{P}(14) \\
\mathrm{Si} / \mathrm{P}(16)\end{array}$ & $\begin{array}{l}{[0,0,0]} \\
{[0,0,0]}\end{array}$ & 7.478 & 7.478 & -145.242 & -24.207 \\
\hline 21 & 38 & $\mathcal{P}$ & $\begin{array}{l}\mathrm{Na} / \mathrm{Va}(3) \\
\mathrm{Si} / \mathrm{P}(12)\end{array}$ & $\begin{array}{c}{[0,0,0]} \\
{[0,-1,0]}\end{array}$ & 7.857 & 7.857 & -445.839 & -37.153 \\
\hline 22 & 42 & $\mathcal{P}$ & $\begin{array}{l}\mathrm{Na} / \mathrm{Va}(3) \\
\mathrm{Si} / \mathrm{P}(13)\end{array}$ & $\begin{array}{c}{[0,0,0]} \\
{[-1,1,0]}\end{array}$ & 8.083 & 8.083 & +276.618 & +23.051 \\
\hline 23 & 44 & $\mathcal{P}$ & $\begin{array}{l}\mathrm{Na} / \mathrm{Va}(3) \\
\mathrm{Si} / \mathrm{P}(14)\end{array}$ & $\begin{array}{c}{[0,0,0]} \\
{[0,-1,0]}\end{array}$ & 8.198 & 8.198 & -377.133 & -31.428 \\
\hline 24 & 46 & $\mathcal{P}$ & $\begin{array}{l}\mathrm{Na} / \mathrm{Va}(3) \\
\mathrm{Na} / \mathrm{Va}(5)\end{array}$ & $\begin{array}{c}{[0,0,0]} \\
{[1,-1,0]}\end{array}$ & 8.483 & 8.483 & +15.930 & +2.655 \\
\hline 25 & 49 & $\mathcal{P}$ & $\begin{array}{l}\mathrm{Si} / \mathrm{P}(14) \\
\mathrm{Na} / \mathrm{Va}(0)\end{array}$ & $\begin{array}{c}{[0,0,0]} \\
{[-1,1,0]}\end{array}$ & 8.570 & 8.570 & -23.865 & -1.989 \\
\hline 26 & 50 & $\mathcal{P}$ & $\begin{array}{l}\mathrm{Si} / \mathrm{P}(14) \\
\mathrm{Si} / \mathrm{P}(15)\end{array}$ & $\begin{array}{c}{[0,0,0]} \\
{[1,-1,0]}\end{array}$ & 8.608 & 8.608 & +130.803 & +10.900 \\
\hline 27 & 52 & $\mathcal{P}$ & $\begin{array}{l}\mathrm{Na} / \mathrm{Va}(3) \\
\mathrm{Na} / \mathrm{Va}(7)\end{array}$ & $\begin{array}{c}{[0,0,0]} \\
{[1,0,-1]}\end{array}$ & 8.736 & 8.736 & -46.095 & -3.841 \\
\hline 28 & 53 & $\mathcal{P}$ & $\begin{array}{l}\mathrm{Na} / \mathrm{Va}(3) \\
\mathrm{Na} / \mathrm{Va}(2)\end{array}$ & $\begin{array}{c}{[0,0,0]} \\
{[0,-1,0]}\end{array}$ & 8.856 & 8.856 & +11.860 & +1.977 \\
\hline 29 & 62 & $\mathcal{P}$ & $\begin{array}{l}\mathrm{Na} / \mathrm{Va}(3) \\
\mathrm{Na} / \mathrm{Va}(3)\end{array}$ & $\begin{array}{c}{[0,0,0]} \\
{[1,0,-1]}\end{array}$ & 9.186 & 9.186 & -68.224 & -11.371 \\
\hline 30 & 63 & $\mathcal{P}$ & $\begin{array}{l}\mathrm{Na} / \mathrm{Va}(3) \\
\mathrm{Na} / \mathrm{Va}(3)\end{array}$ & $\begin{array}{c}{[0,0,0]} \\
{[1,0,-1]}\end{array}$ & 9.186 & 9.186 & -142.789 & -11.899 \\
\hline 31 & 64 & $\mathcal{P}$ & $\begin{array}{l}\mathrm{Si} / \mathrm{P}(14) \\
\mathrm{Si} / \mathrm{P}(14)\end{array}$ & $\begin{array}{c}{[0,0,0]} \\
{[0,1,-1]}\end{array}$ & 9.186 & 9.186 & -215.821 & -17.985 \\
\hline 33 & 65 & $\mathcal{P}$ & $\begin{array}{l}\mathrm{Na} / \mathrm{Va}(0) \\
\mathrm{Na} / \mathrm{Va}(0)\end{array}$ & $\begin{array}{c}{[0,0,0]} \\
{[1,0,-1]}\end{array}$ & 9.186 & 9.186 & -561.834 & -93.639 \\
\hline 33 & 66 & $\mathcal{P}$ & $\begin{array}{l}\mathrm{Si} / \mathrm{P}(14) \\
\mathrm{Si} / \mathrm{P}(14)\end{array}$ & $\begin{array}{c}{[0,0,0]} \\
{[0,1,-1]}\end{array}$ & 9.186 & 9.186 & -21.014 & -3.502 \\
\hline 34 & 69 & $\mathcal{P}$ & $\begin{array}{l}\mathrm{Na} / \mathrm{Va}(3) \\
\mathrm{Si} / \mathrm{P}(14)\end{array}$ & $\begin{array}{c}{[0,0,0]} \\
{[0,0,-1]}\end{array}$ & 9.309 & 9.309 & +165.373 & +13.781 \\
\hline 35 & 71 & $\mathcal{P}$ & $\begin{array}{l}\mathrm{Si} / \mathrm{P}(14) \\
\mathrm{Si} / \mathrm{P}(16)\end{array}$ & $\begin{array}{c}{[0,0,0]} \\
{[-1,1,0]}\end{array}$ & 9.510 & 9.510 & -142.597 & -23.766 \\
\hline 36 & 73 & $\mathcal{P}$ & $\mathrm{Na} / \mathrm{Va}(3)$ & {$[0,0,0]$} & 9.633 & 9.633 & +21.698 & +1.808 \\
\hline
\end{tabular}




\begin{tabular}{|c|c|c|c|c|c|c|c|c|}
\hline & & & $\mathrm{Si} / \mathrm{P}(13)$ & {$[0,-1,0]$} & & & & \\
\hline 37 & 79 & $\mathcal{P}$ & $\begin{array}{l}\mathrm{Na} / \mathrm{Va}(3) \\
\mathrm{Si} / \mathrm{P}(17)\end{array}$ & $\begin{array}{c}{[0,0,0]} \\
{[-1,0,1]}\end{array}$ & 9.838 & 9.838 & +419.493 & +34.958 \\
\hline 38 & 82 & $\mathcal{P}$ & $\begin{array}{l}\mathrm{Na} / \mathrm{Va}(3) \\
\mathrm{Si} / \mathrm{P}(12)\end{array}$ & $\begin{array}{c}{[0,0,0]} \\
{[-1,-1,1]}\end{array}$ & 9.879 & 9.879 & +183.989 & +15.332 \\
\hline Index & Cluster Index & Type & Site(Label) & Cell & Min. $(\AA)$ & $\operatorname{Max} .(\AA)$ & ECI (meV) & $\mathrm{ECI} / \mathrm{M}(\mathrm{meV})$ \\
\hline 39 & 84 & $\mathcal{T}$ & $\begin{array}{l}\mathrm{Na} / \mathrm{Va}(3) \\
\mathrm{Na} / \mathrm{Va}(0) \\
\mathrm{Si} / \mathrm{P}(14)\end{array}$ & $\begin{array}{l}{[0,0,0]} \\
{[0,0,0]} \\
{[0,0,0]}\end{array}$ & 3.056 & 3.739 & -632.141 & -52.678 \\
\hline 40 & 85 & $\mathcal{T}$ & $\begin{array}{l}\mathrm{Na} / \mathrm{Va}(3) \\
\mathrm{Na} / \mathrm{Va}(0) \\
\mathrm{Si} / \mathrm{P}(13)\end{array}$ & $\begin{array}{l}{[0,0,0]} \\
{[0,0,0]} \\
{[0,0,0]}\end{array}$ & 3.162 & 3.739 & -343.491 & -28.624 \\
\hline 41 & 86 & $\mathcal{T}$ & $\begin{array}{l}\mathrm{Na} / \mathrm{Va}(3) \\
\mathrm{Na} / \mathrm{Va}(0) \\
\mathrm{Si} / \mathrm{P}(17)\end{array}$ & $\begin{array}{l}{[0,0,0]} \\
{[0,0,0]} \\
{[0,0,0]}\end{array}$ & 3.478 & 3.739 & +112.125 & +9.344 \\
\hline 42 & 87 & $\mathcal{T}$ & $\begin{array}{l}\mathrm{Na} / \mathrm{Va}(3) \\
\mathrm{Si} / \mathrm{P}(14) \\
\mathrm{Si} / \mathrm{P}(16)\end{array}$ & $\begin{array}{l}{[0,0,0]} \\
{[0,0,0]} \\
{[0,0,1]}\end{array}$ & 3.056 & 4.626 & -8.603 & -0.717 \\
\hline 43 & 88 & $\mathcal{T}$ & $\begin{array}{l}\mathrm{Na} / \mathrm{Va}(3) \\
\mathrm{Si} / \mathrm{P}(14) \\
\mathrm{Si} / \mathrm{P}(12)\end{array}$ & $\begin{array}{c}{[0,0,0]} \\
{[0,0,0]} \\
{[0,-1,1]}\end{array}$ & 3.056 & 4.700 & +147.373 & +24.562 \\
\hline 44 & 89 & $\mathcal{T}$ & $\begin{array}{l}\mathrm{Si} / \mathrm{P}(14) \\
\mathrm{Si} / \mathrm{P}(12) \\
\mathrm{Si} / \mathrm{P}(13)\end{array}$ & $\begin{array}{c}{[0,0,0]} \\
{[0,-1,1]} \\
{[-1,0,1]}\end{array}$ & 4.700 & 4.700 & +36.538 & +18.269 \\
\hline 45 & 91 & $\mathcal{T}$ & $\begin{array}{l}\mathrm{Na} / \mathrm{Va}(3) \\
\mathrm{Na} / \mathrm{Va}(6) \\
\mathrm{Si} / \mathrm{P}(13)\end{array}$ & $\begin{array}{l}{[0,0,0]} \\
{[0,0,0]} \\
{[0,0,0]}\end{array}$ & 3.162 & 4.727 & +210.952 & +17.579 \\
\hline 46 & 92 & $\mathcal{T}$ & $\begin{array}{l}\mathrm{Na} / \mathrm{Va}(3) \\
\mathrm{Na} / \mathrm{Va}(0) \\
\mathrm{Na} / \mathrm{Va}(6)\end{array}$ & $\begin{array}{l}{[0,0,0]} \\
{[0,0,0]} \\
{[0,0,0]}\end{array}$ & 3.477 & 4.727 & +2969.345 & +247.445 \\
\hline 47 & 93 & $\mathcal{T}$ & $\begin{array}{l}\mathrm{Na} / \mathrm{Va}(3) \\
\mathrm{Si} / \mathrm{P}(14) \\
\mathrm{Si} / \mathrm{P}(17)\end{array}$ & $\begin{array}{l}{[0,0,0]} \\
{[0,0,0]} \\
{[0,0,0]}\end{array}$ & 3.056 & 4.922 & +124.056 & +10.338 \\
\hline 48 & 96 & $\mathcal{T}$ & $\begin{array}{l}\mathrm{Si} / \mathrm{P}(14) \\
\mathrm{Si} / \mathrm{P}(15) \\
\mathrm{Si} / \mathrm{P}(16)\end{array}$ & $\begin{array}{c}{[0,0,0]} \\
{[0,0,0]} \\
{[-1,0,1]}\end{array}$ & 4.626 & 4.922 & +101.874 & +8.490 \\
\hline 49 & 98 & $\mathcal{T}$ & $\begin{array}{l}\mathrm{Na} / \mathrm{Va}(3) \\
\mathrm{Na} / \mathrm{Va}(4) \\
\mathrm{Si} / \mathrm{P}(13)\end{array}$ & $\begin{array}{c}{[0,0,0]} \\
{[1,-1,0]} \\
{[0,0,0]}\end{array}$ & 3.055 & 5.102 & -167.327 & -13.944 \\
\hline 50 & 99 & $\mathcal{T}$ & $\mathrm{Na} / \mathrm{Va}(3)$ & {$[0,0,0]$} & 3.4779 & 5.102 & -483.709 & -40.309 \\
\hline
\end{tabular}




\begin{tabular}{|c|c|c|c|c|c|c|c|c|}
\hline & & & $\begin{array}{l}\mathrm{Na} / \mathrm{Va}(4) \\
\mathrm{Na} / \mathrm{Va}(1)\end{array}$ & $\begin{array}{c}{[1,-1,0]} \\
{[1,0,1]}\end{array}$ & & & & \\
\hline 51 & 100 & $\mathcal{T}$ & $\begin{array}{l}\mathrm{Na} / \mathrm{Va}(3) \\
\mathrm{Na} / \mathrm{Va}(4) \\
\mathrm{Na} / \mathrm{Va}(7)\end{array}$ & $\begin{array}{c}{[0,0,0]} \\
{[1,-1,0]} \\
{[1,0,0]}\end{array}$ & 4.727 & 5.102 & +85.713 & +7.143 \\
\hline 52 & 101 & $\mathcal{T}$ & $\begin{array}{l}\mathrm{Na} / \mathrm{Va}(0) \\
\mathrm{Na} / \mathrm{Va}(4) \\
\mathrm{Na} / \mathrm{Va}(6)\end{array}$ & $\begin{array}{c}{[0,0,0]} \\
{[1,-1,0]} \\
{[0,0,0]}\end{array}$ & 4.727 & 5.102 & -193.556 & -16.130 \\
\hline 53 & 102 & $\mathcal{T}$ & $\begin{array}{l}\mathrm{Na} / \mathrm{Va}(3) \\
\mathrm{Na} / \mathrm{Va}(4) \\
\mathrm{Na} / \mathrm{Va}(2)\end{array}$ & $\begin{array}{c}{[0,0,0]} \\
{[1,-1,0]} \\
{[0,-1,1]}\end{array}$ & 5.1025 & 5.1025 & -96.748 & -24.187 \\
\hline 54 & 104 & $\mathcal{T}$ & $\begin{array}{l}\mathrm{Si} / \mathrm{P}(14) \\
\mathrm{Na} / \mathrm{Va}(0) \\
\mathrm{Si} / \mathrm{P}(12)\end{array}$ & $\begin{array}{l}{[0,0,0]} \\
{[0,0,0]} \\
{[0,0,0]}\end{array}$ & 3.739 & 5.629 & +913.076 & +76.090 \\
\hline 55 & 105 & $\mathcal{T}$ & $\begin{array}{l}\mathrm{Si} / \mathrm{P}(14) \\
\mathrm{Si} / \mathrm{P}(12) \\
\mathrm{Si} / \mathrm{P}(17)\end{array}$ & $\begin{array}{l}{[0,0,0]} \\
{[0,0,0]} \\
{[0,0,0]} \\
\end{array}$ & 4.626 & 5.629 & +183.298 & +15.275 \\
\hline 56 & 107 & $\mathcal{T}$ & $\begin{array}{l}\mathrm{Si} / \mathrm{P}(14) \\
\mathrm{Si} / \mathrm{P}(12) \\
\mathrm{Si} / \mathrm{P}(15)\end{array}$ & $\begin{array}{l}{[0,0,0]} \\
{[0,0,0]} \\
{[0,0,0]}\end{array}$ & 4.922 & 5.629 & -64.742 & -5.395 \\
\hline 57 & 108 & $\mathcal{T}$ & $\begin{array}{l}\mathrm{Si} / \mathrm{P}(14) \\
\mathrm{Si} / \mathrm{P}(12) \\
\mathrm{Si} / \mathrm{P}(13)\end{array}$ & $\begin{array}{l}{[0,0,0]} \\
{[0,0,0]} \\
{[0,0,0]}\end{array}$ & 5.623 & 5.623 & -110.756 & -27.689 \\
\hline 58 & 109 & $\mathcal{T}$ & $\begin{array}{l}\mathrm{Na} / \mathrm{Va}(3) \\
\mathrm{Si} / \mathrm{P}(14) \\
\mathrm{Na} / \mathrm{Va}(2)\end{array}$ & $\begin{array}{c}{[0,0,0]} \\
{[0,0,0]} \\
{[-1,0,1]}\end{array}$ & 3.056 & 5.733 & -15.573 & -2.595 \\
\hline 59 & 110 & $\mathcal{T}$ & $\begin{array}{l}\mathrm{Na} / \mathrm{Va}(3) \\
\mathrm{Na} / \mathrm{Va}(6) \\
\mathrm{Na} / \mathrm{Va}(5)\end{array}$ & $\begin{array}{c}{[0,0,0]} \\
{[0,0,0]} \\
{[0,-1,1]}\end{array}$ & 4.727 & 5.733 & -237.045 & -19.754 \\
\hline 60 & 111 & $\mathcal{T}$ & $\begin{array}{l}\mathrm{Na} / \mathrm{Va}(3) \\
\mathrm{Na} / \mathrm{Va}(4) \\
\mathrm{Na} / \mathrm{Va}(2)\end{array}$ & $\begin{array}{c}{[0,0,0]} \\
{[1,-1,0]} \\
{[0,0,0]}\end{array}$ & 5.103 & 5.733 & -54.373 & -9.062 \\
\hline 61 & 112 & $\mathcal{T}$ & $\begin{array}{l}\mathrm{Na} / \mathrm{Va}(3) \\
\mathrm{Na} / \mathrm{Va}(4) \\
\mathrm{Na} / \mathrm{Va}(2)\end{array}$ & $\begin{array}{c}{[0,0,0]} \\
{[0,-1,1]} \\
{[-1,0,1]}\end{array}$ & 5.733 & 5.733 & -32.485 & -16.243 \\
\hline Index & Cluster Index & Type & Site(Label) & Cell & Min. (̊̊) & Max. (̊̊) & ECI (meV) & $\mathrm{ECI} / \mathrm{M}(\mathrm{meV})$ \\
\hline 62 & 113 & $\mathcal{Q}$ & $\begin{array}{l}\mathrm{Na} / \mathrm{Va}(3) \\
\mathrm{Na} / \mathrm{Va}(0) \\
\mathrm{Na} / \mathrm{Va}(6) \\
\mathrm{Si} / \mathrm{P}(17)\end{array}$ & $\begin{array}{l}{[0,0,0]} \\
{[0,0,0]} \\
{[0,0,0]} \\
{[0,0,0]}\end{array}$ & 3.162 & 4.727 & -648.492 & -54.041 \\
\hline
\end{tabular}




\begin{tabular}{|c|c|c|c|c|c|c|c|c|}
\hline 63 & 115 & $\mathcal{Q}$ & $\begin{array}{l}\mathrm{Na} / \mathrm{Va}(3) \\
\mathrm{Na} / \mathrm{Va}(6) \\
\mathrm{Si} / \mathrm{P}(13) \\
\mathrm{Si} / \mathrm{P}(17)\end{array}$ & $\begin{array}{l}{[0,0,0]} \\
{[0,0,0]} \\
{[0,0,0]} \\
{[0,0,0]}\end{array}$ & 3.056 & 4.922 & -125.232 & -10.436 \\
\hline 64 & 118 & $\mathcal{Q}$ & $\begin{array}{l}\mathrm{Na} / \mathrm{Va}(3) \\
\mathrm{Na} / \mathrm{Va}(0) \\
\mathrm{Si} / \mathrm{P}(13) \\
\mathrm{Si} / \mathrm{P}(17)\end{array}$ & $\begin{array}{l}{[0,0,0]} \\
{[0,0,0]} \\
{[0,0,0]} \\
{[0,0,0]}\end{array}$ & 3.162 & 4.922 & -748.192 & -62.349 \\
\hline 65 & 119 & $\mathcal{Q}$ & $\begin{array}{c}\mathrm{Na} / \mathrm{Va}(3) \\
\mathrm{Si} / \mathrm{P}(14) \\
\mathrm{Na} / \mathrm{Va}(5) \\
\mathrm{Si} / \mathrm{P}(16)\end{array}$ & $\begin{array}{l}{[0,0,0]} \\
{[0,0,0]} \\
{[0,0,1]} \\
{[0,0,1]}\end{array}$ & 3.056 & 4.981 & -55.110 & -9.185 \\
\hline
\end{tabular}

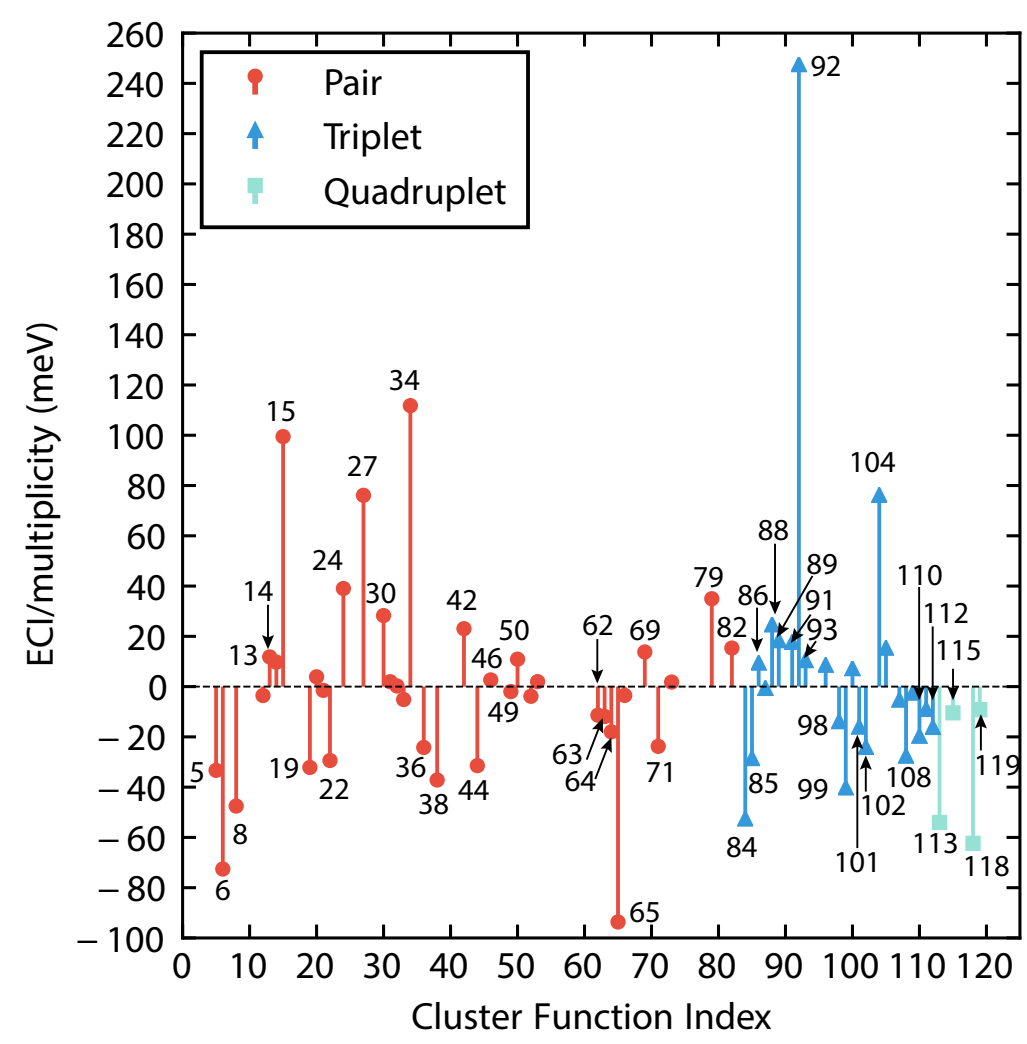

Figure S1: Relevant ECIs as function vs. their cluster index as fully detailed in Table S2. The point term is not shown. 


\section{S3 Basis of the Cluster Expansion and ECI assignation}

An occupational basis was utilised and thus $\sigma$ is assigned $\mathrm{Na}=0, \mathrm{Va}=1$, and $\mathrm{Si}=0, \mathrm{P}$ $=1$. Therefore only clusters which are occupied by Va (on Na/Va sites) and/or P (on Si/P sites) in a given structure contribute non-zero ECIs to the overall CE model. The sign of the ECIs identify whether the interactions are attractive (negative ECIs) or repulsive (positive ECIs) between Va, P and across Va and P. While an attractive ECI favors all sites in a given cluster to be occupied by Va and/or by $\mathrm{P}$, a repulsive ECI favors the occupation of at least one of the sites in the cluster by Na or Si. Tables S3, S4, and S5 lists the most prominent, in terms of magnitude, attractive and repulsive pair, triplet, and quadruplet ECIs, respectively.

Table S3: Unique ECI pairs (in meV) normalised by their multiplicity.

\begin{tabular}{llr}
\hline ECI \# & Species & ECI \\
\hline \multicolumn{3}{c}{ Attractive } \\
5 & Va-P & -33.313 \\
6 & Va-Va & -72.572 \\
8 & Va-P & -47.521 \\
19 & Va-P & -32.152 \\
22 & Va-P & -29.395 \\
36 & P-P & -24.207 \\
38 & Va-P & -37.153 \\
44 & Va-P & -31.428 \\
64 & $\mathrm{P}-\mathrm{P}$ & -17.985 \\
65 & Va-Va & -93.639 \\
71 & Va-P & -23.766 \\
\hline \multicolumn{3}{c}{ Repulsive } \\
15 & Va-Va & +99.460 \\
24 & Va-Va & +39.037 \\
27 & Va-Va & +76.111 \\
30 & Va-P & +28.269 \\
34 & Va-Va & +111.779 \\
42 & Va-P & +23.051 \\
79 & Va-P & +34.958 \\
\hline
\end{tabular}


Table S4: Unique ECI triplets (in meV) normalised by their multiplicity.

\begin{tabular}{llr}
\hline ECI \# & Species & ECI \\
\hline \multicolumn{3}{c}{ Attractive } \\
84 & Va-Va-P & -52.678 \\
85 & Va-Va-P & -28.624 \\
99 & Va-Va-Va & -40.309 \\
102 & Va-Va-Va & -24.187 \\
\hline \multicolumn{3}{c}{ Repulsive } \\
92 & Va-Va-Va & +247.445 \\
104 & P-Va-P & +76.090 \\
\hline
\end{tabular}

Table S5: Unique ECI quadruplets (in meV) normalised by their multiplicity.

\begin{tabular}{llr}
\hline ECI \# & Species & ECI/M (meV) \\
\hline \multicolumn{3}{c}{ Attractive } \\
113 & Va-Va-Va-P & -54.041 \\
118 & Va-Va-P-P & -62.349 \\
\hline
\end{tabular}

\section{S4 Thermodynamic Integration}

As shown in Figure S2, the grand-canonical Monte Carlo (MC) scans were performed in the chemical potential $(\mu)$ and temperature $(T)$ space. The scan started at $T=5 \mathrm{~K}$ and up to $1605 \mathrm{~K}$ with a step $\Delta T=5 \mathrm{~K}$ at $\mu=-1,0$ and $1 \mathrm{eV} /$ f.u. Then at every $T, \mu$ was scanned in both forward ( $\mu=-1.0$ to $1.0 \mathrm{eV} /$ f.u. $)$ and backward $(\mu=1.0$ to $-1.0 \mathrm{eV} /$ f.u. $)$ directions with a step size of $\Delta \mu=0.005 \mathrm{eV} /$ f.u. as shown in Figure S2. In general, $\mu$ was scanned across 2 concentration ranges, namely, between $\mathrm{x}=0$ and $2(\mu=-1.0$ to $0.0 \mathrm{eV} /$ f.u. $)$, and $\mathrm{x}=2$ and 3 ( $\mu=0.0$ to $1.0 \mathrm{eV} /$ f.u. $)$, due to the existence of the 3 ground-state structures on the convex hull ( $\mathrm{x}=0,2$ and 3 , see manuscript).

The phase boundary was found at the intersections of the grand-canonical potential energy $\Phi^{\alpha}$ for each phase $\alpha$ (A, B and C) as defined in Figure S2. $\Phi$ is defined by Eq. 1

$$
\Phi=[E-\mathrm{T} S]-\mu c
$$



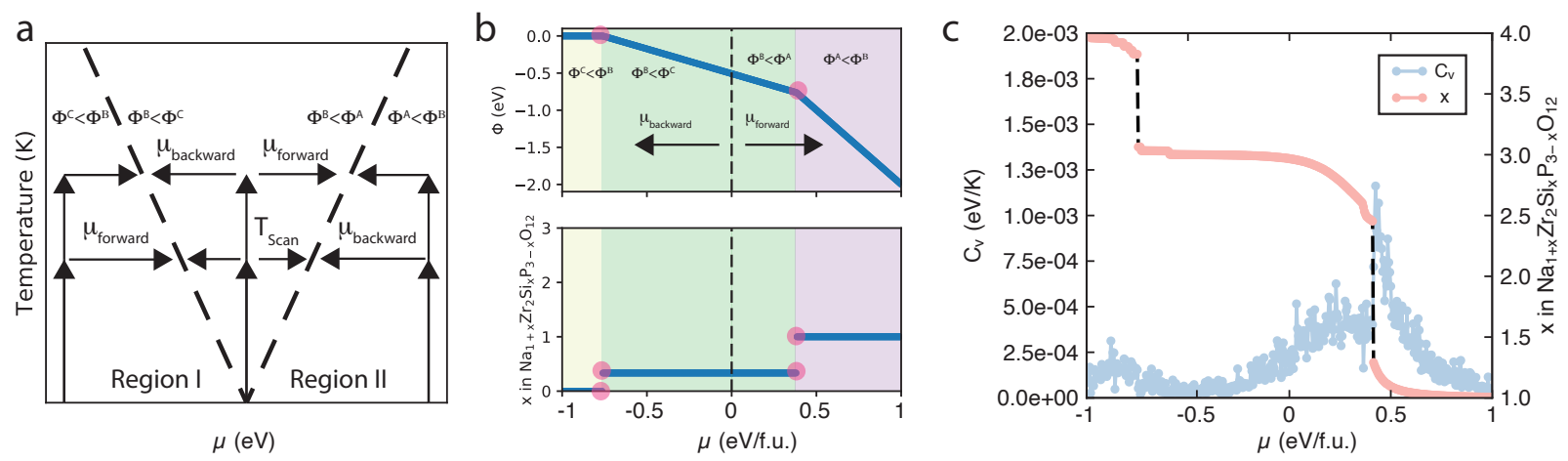

In panel

Figure S2: a Schematic showing how the phase boundary (dashed lines) was identified in the $(\mu, T)$ space. The arrows show both the MC scan and the thermodynamic integration directions. At phase boundaries, potential surfaces $\Phi^{\alpha}(\mu, T)$ on the both sides intersects with each other. The phase boundaries in the $(x, T)$ space are then converted from the compositions at the phase boundary in $(\mu, T)$ space. $\mathbf{b}$ An example (at $\mathrm{T}=105 \mathrm{~K}$ ) of the grand potential $(\Phi)$ depending on chemical potential $(\mu, T)$, along with the strategy to choose the phase boundaries (pink circles) is shown. c Variation of composition $x$ and normalized heat capacity $C_{v}$ vs. $\mu$, at $\mathrm{T}=445 \mathrm{~K}$, as obtained from the Monte Carlo simulations is displayed. Discontinuities in the chemical potential $\mu$ represent phase transitions at specific concentrations $x$ and are indicated by dashed lines in black.

where $E$ is the total energy predicted by the cluster expansion model, $S$ is the configurational entropy and $c$ is the parametric composition. The parametric composition $c$ in $\mathrm{Na}_{1+\mathrm{x}} \mathrm{Zr}_{2} \mathrm{Si}_{\mathrm{x}} \mathrm{P}_{3-\mathrm{x}} \mathrm{O}_{12}$ is defined as in Eq. 2.

$$
c=1-\frac{x}{3} \text { with } 0 \leq c \leq 1
$$

For Monte Carlo scans at fixed $\mu$ and variable $T, \Phi$ is calculated using the thermodynamic integration in Eq. 3.

$$
\begin{aligned}
\Phi(\beta, \mu) & =\frac{\beta_{0}}{\beta} \Phi_{0}\left(\beta_{0}, \mu\right)+\frac{1}{\beta} \int_{\beta_{0}}^{\beta}[E-\mu c] d \beta \\
\text { with } \Phi_{0}\left(\beta_{0}, \mu\right) & =E-\mu c
\end{aligned}
$$

where $\beta=1 /\left(k_{B} T\right)$ and $k_{B}$ is the Boltzmann constant. 
In Monte Carlo scans at variable $\mu$ and fixed $T, \Phi$ is defined in Eq. 5.

$$
\begin{aligned}
\Phi(\beta, \mu) & =\Phi_{0}\left(\beta, \mu_{0}\right)-\frac{1}{\beta} \int_{\mu_{0}}^{\mu} c d \mu \\
\text { with } \Phi_{0}\left(\beta, \mu_{0}\right) & =\Phi_{\text {heating }}\left(\beta, \mu_{0}\right)
\end{aligned}
$$

Since the entropy effects are negligible at low temperatures (e.g., $T=5 \mathrm{~K}$ ), the starting values of $\Phi_{0}$ in $T$ scans at $5 \mathrm{~K}$ are taken as $\Phi_{0}=E-\mu c$. The thermodynamic integration at each $\mu$ starts from the $\Phi_{\text {heating }}\left(T, \mu_{0}\right)$ where $\mu_{0}=-1,0$ and $1 \mathrm{eV} /$ f.u., and is scanned both forward and backward in the Region I and Region II as shown in Figure S2a. One of the examples is shown in Figure S2b.

After the thermodynamic integration, the phase boundary is identified by the intersection of grand-canonical potential envelops in the $(\mu, \mathrm{T})$ space (dashed lines in Figure S2a) which is then converted into the $(x, \mathrm{~T})$ space. When the intersections is not well defined by the numerical data, discontinuities in $c$ vs. $\mu$ and $C_{v}$ vs. $\mu$ curves (see Figure S2c) are considered and the phase boundaries identified. 


\section{S5 Example of Monte Carlo Snapshot}

Figure S3 shows a snapshot from the Monte Carlo simulations and three ground state structures at $\mathrm{x}=0,2$ and 3 in $\mathrm{Na}_{1+\mathrm{x}} \mathrm{Zr}_{2} \mathrm{Si}_{\mathrm{x}} \mathrm{P}_{3-\mathrm{x}} \mathrm{O}_{12}$ (right panel).
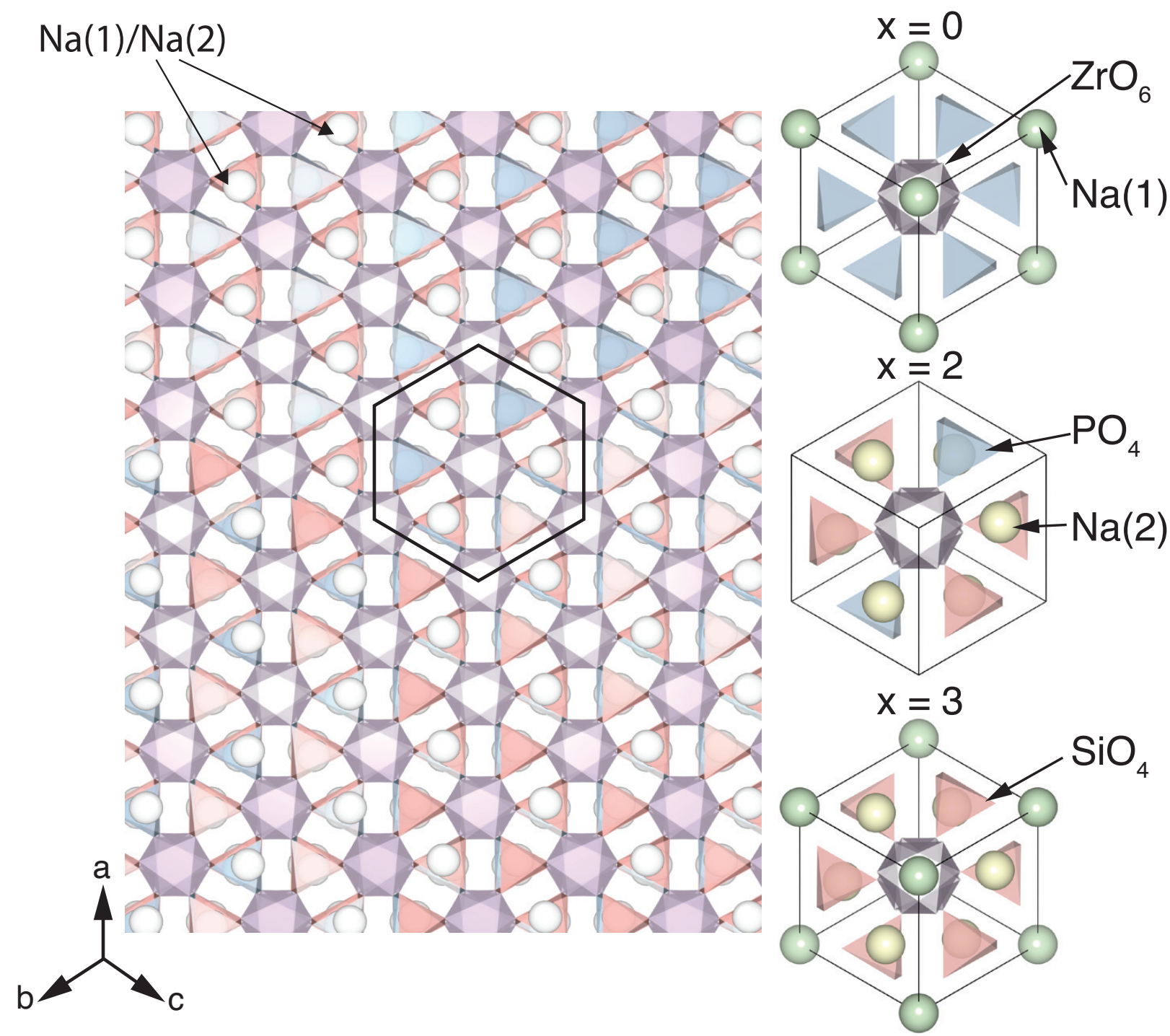

Figure S3: In the left panel, a portion of a snapshot of a Monte Carlo simulation $(\mathrm{x}=2, \mathrm{~T}$ $=445 \mathrm{~K}$ ), where a primitive cell of $\mathrm{Na}_{1+\mathrm{x}} \mathrm{Zr}_{2} \mathrm{Si}_{\mathrm{x}} \mathrm{P}_{3-\mathrm{x}} \mathrm{O}_{12}$ is marked by the black hexagon ( $\mathrm{Na}$ at both $\mathrm{Na}(1)$ and $\mathrm{Na}(2)$ sites are coloured silver). The primitive cells of the three ground state structures at $\mathrm{x}=0,2$ and 3 for $\mathrm{Na}_{1+\mathrm{x}} \mathrm{Zr}_{2} \mathrm{Si}_{\mathrm{x}} \mathrm{P}_{3-\mathrm{x}} \mathrm{O}_{12}$ are shown on the right. 


\section{References}

(1) Qui, D.; Capponi, J.; Joubert, J.; Shannon, R. Crystal structure and ionic conductivity in $\mathrm{Na}_{4} \mathrm{Zr}_{2} \mathrm{Si}_{3} \mathrm{O}_{12}$. J. Solid State Chem. 1981, 39, 219-229. 